\title{
An integrated model system for coastal flood prediction with a case history for Walcott, UK, on 9 November 2007
}

\author{
P. Stansby ${ }^{1}$, N. Chini', D. Apsley ${ }^{1}$, A. Borthwick ${ }^{2}$, L. Bricheno ${ }^{3}$, J. Horrillo-Caraballo ${ }^{4}$, M. McCabe', \\ D. Reeve ${ }^{4}$, B.D. Rogers ${ }^{1}$, A. Saulter ${ }^{5}$, A. Scott ${ }^{6}$, C. Wilson ${ }^{3}$, J. Wolf ${ }^{3}$ and K. Yan ${ }^{7}$ \\ 1 University of Manchester, Manchester, UK \\ 2 University College Cork, Cork, Ireland \\ 3 National Oceanography Centre, Liverpool, UK \\ 4 Swansea University, Swansea, UK \\ 5 Met Office, Exeter, UK \\ 6 Environment Agency, Bristol, UK \\ 7 Cardiff University, Cardiff, UK
}

\author{
Correspondence \\ Peter Stansby, Mechanical, Aerospace and \\ Civil Engineering, University of \\ Manchester, Sackville St, Manchester \\ M13 9PL, UK \\ Tel: + 441613064598 \\ Fax: +44161306 3755 \\ Email: p.k.stansby@manchester.ac.uk
}

DOI: $10.1111 / \mathrm{jfr} 3.12001$

Key words

Climate change; coastal; flood; modelling.

\begin{abstract}
An integrated model system is based on downscaling from climate models, to wave climate and continental shelf models for tides and surge, to coastal models for waves and water levels, to beach levels and overtopping of sea defences and inundation. Present operational practice in the UK is described. The model system is applied to the prediction of flooding at Walcott on 9 November 2007. Inundation levels are predicted in reasonable agreement with those at certain residential properties in Walcott as reported by the occupants. The effect of time-varying and time-averaged overtopping discharge is considered. Sensitivity of overtopping and inundation to uncertainties in nearshore wave height and water level is analysed, with the greatest sensitivity being to water level. Extreme joint probability analysis is undertaken, showing the event to be close to a 1 in 100-year event. Finally, the effects of different rates of sea level rise and a climate change scenario are investigated for 2100; the simulations indicate that the return period of the equivalent 2007 event could reduce to less than 2 years with a $0.5 \mathrm{~m}$ sea level rise.
\end{abstract}

\section{Introduction}

The aim of this paper is to describe an integrated model system for the prediction of coastal flooding; this was undertaken as part of the UK Flood Risk Management Research Consortium. Climate models from the Met Office (http:// www.metoffice.gov.uk) provide boundary conditions for regional climate models, which in turn provide boundary conditions for wave climate and continental shelf models of the National Oceanography Centre (NOC; http://www. noc.ac.uk). These models provide further boundary conditions for modelling nearshore waves and water levels due to tides, surge and wave set-up, which are the parameters driving overtopping, inundation and breaching at the coast. Importantly, sea level rise and climate change are taken into account. The model components are state-of-the-art and recently developed in the case of beach profile prediction, overtopping and joint probability analysis. In this paper, the methods are applied for a particular flood event that occurred in Walcott in North Norfolk, UK, on 9 November 2007. The coastline at Walcott is orientated approximately north-west/south-east and is prone to attack by waves in the North Sea, especially when the wind blows from the northeast; see Figure 1. The danger increases when this wind is combined with a North Sea surge, which can raise the still water level of the sea by up to $2 \mathrm{~m}$ above the predicted tidal level. Such conditions have caused disastrous flooding in Walcott, as in 1953 (Wallingford, 2002), and more recently in 2007. The offshore conditions have been provided from models, the beach levels were measured regularly before the event and inshore flood levels were obtained by interviewing residents in 2009. In addition, modelled water levels could be compared with field data from the Environment Agency (EA; http://www.environment-agency.gov.uk) tide gauge at Lowestoft. The generic situation is of an open coast with wave overtopping a sea wall causing flooding.

Figure 2 shows the road map for the overall study, which includes the sequence of models and analysis. The structure 
of the paper is as follows: the second section describes the present operational system, and the third section describes the modelling system for offshore wind, waves and surge for the Walcott event. The fourth section describes the modelling of nearshore waves and water levels by transformation

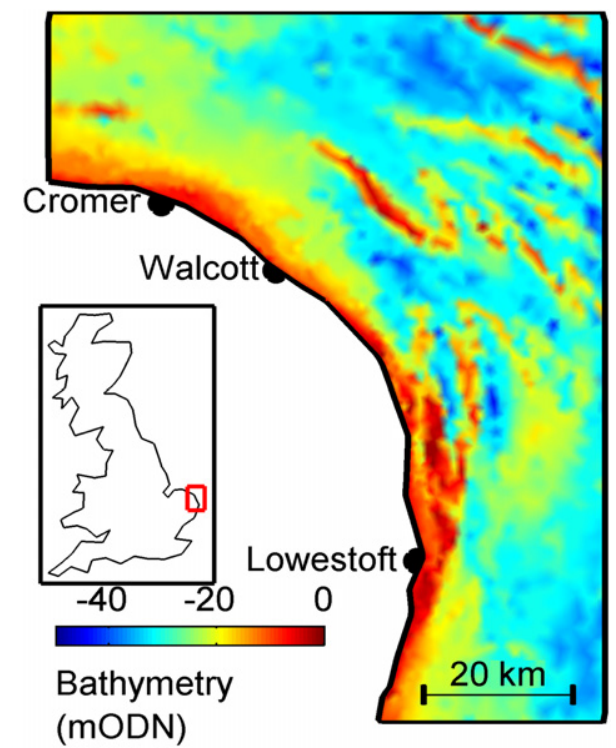

Figure 1 Map showing the bathymetry of the coastal domain and the location of Walcott, Cromer and Lowestoft. from the offshore conditions, and the fifth section describes the modelling of beach levels. The sixth section describes wave overtopping and the seventh section describes inundation. The eighth section analyses the effects of climate change and sea level rise, and the ninth section analyses those of uncertainties.

\section{Operational marine forecasting in the UK}

Coastal flood warnings are presently issued based on forecasts that aim to determine the risk of an event hours to days in advance. The system set-up to deliver these forecasts for the UK (Figure 3 ) is designed based on the necessity to

- represent accurately far-field storm systems that strongly force waves and surges offshore;

- integrate a forecast surge component with the astronomical tide;

- represent the impact of combined tide, surge and waveinduced water levels at the shoreline in terms of flood risk for the surrounding hinterland;

- run quickly and robustly on existing computing infrastructure in order to allow the regular update and review of forecasts with a time horizon up to several days in advance of an event.

Flood warnings are issued from regional offices manned by EA flood forecasters, but each centre works from a

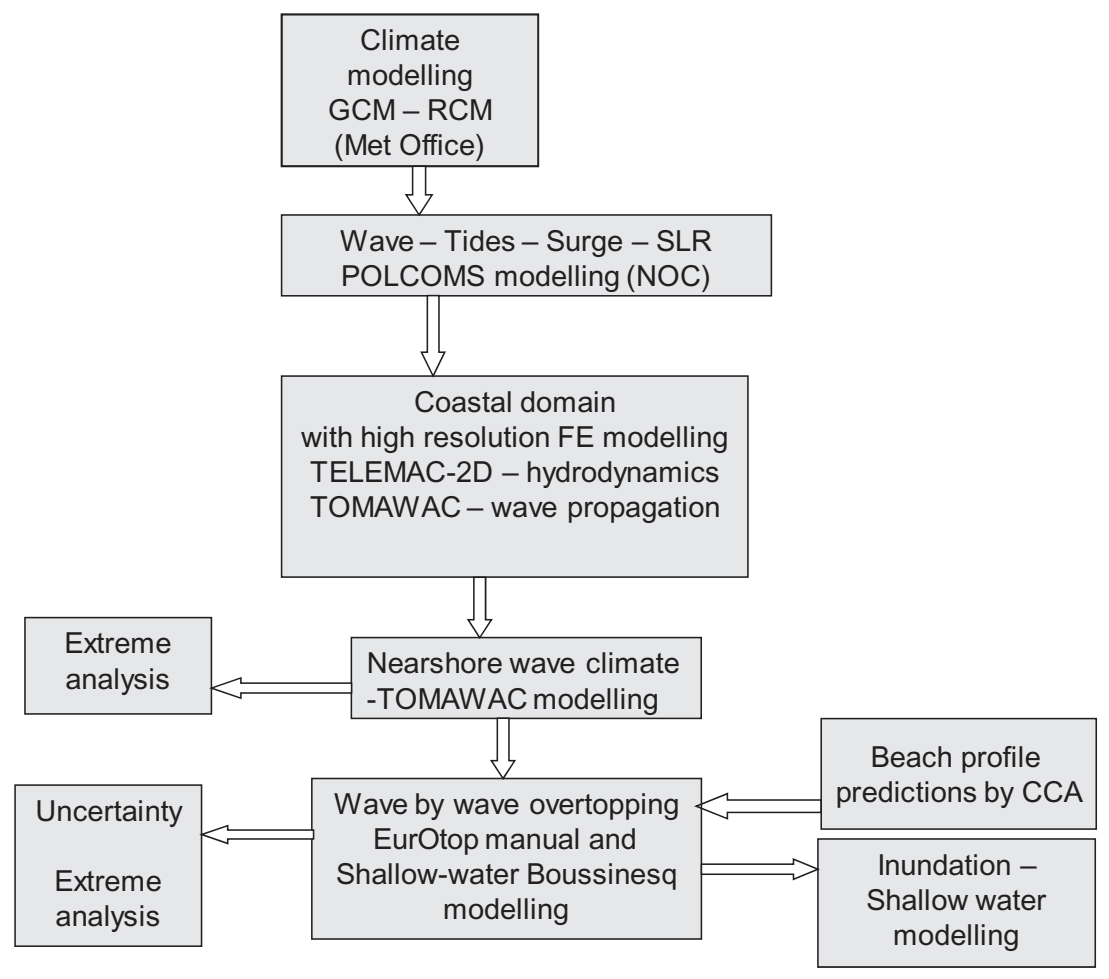

Figure 2 Road map. 


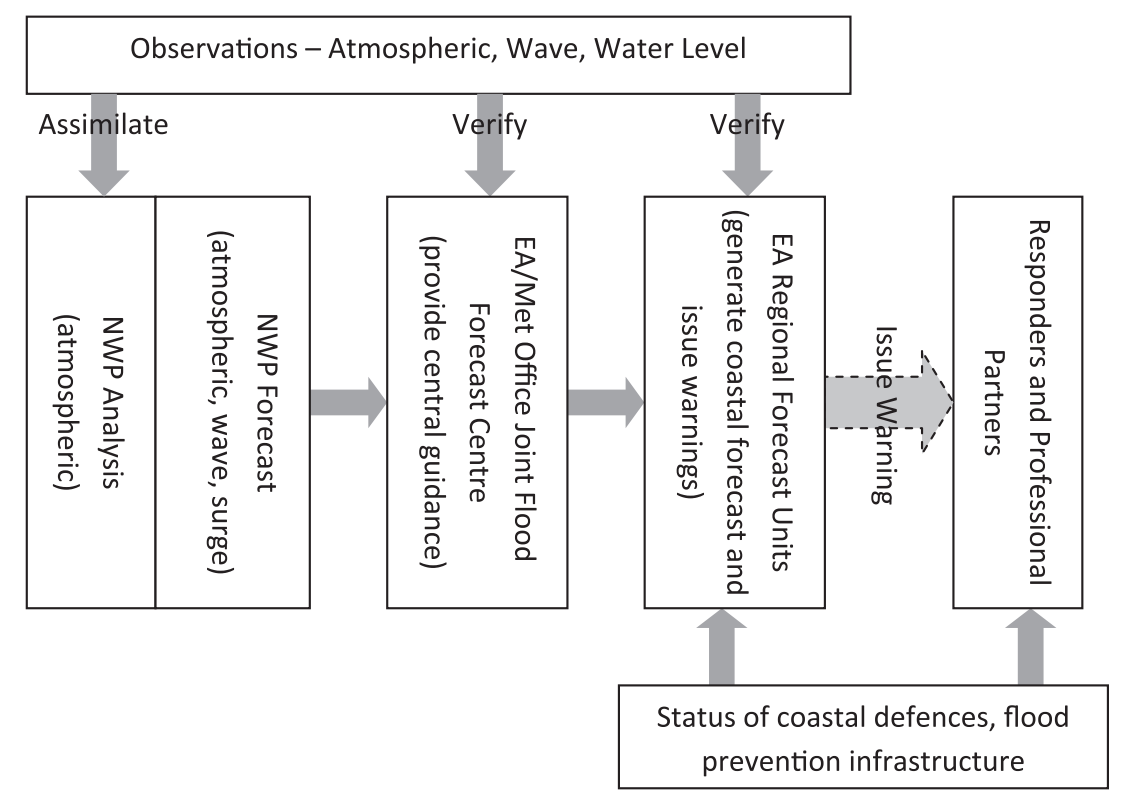

Figure 3 Schematic of the system used to provide coastal flood warnings for the UK.

Table 1 UK regional Numerical Weather Prediction (NWP) models run at the Met Office and directly contributing to coastal flood warning forecasts. Current at March 2011

\begin{tabular}{lllcc}
\hline Model & Configuration name/domain & Parameters & Resolution & Update cycle \\
\hline Unified Model & North Atlantic European & Atmospheric & $12 \mathrm{~km}$ & $4 \times$ daily \\
& Regional ensemble (24 members) & & $18 \mathrm{~km}$ & $12 \mathrm{~km}$ \\
Continental Shelf Model & & $2 \times$ daily \\
& CS3-X (UK-wide) & Tide/surge & $2 \mathrm{~km}$ & $4 \mathrm{~km}$ \\
& Bristol Channel & & $12 \mathrm{~km}$ & $2 \times$ daily \\
& Severn Estuary & Tide/surge & $12 \mathrm{~km}$ & $4 \times$ daily \\
\hline
\end{tabular}

${ }^{\dagger}$ Developed by National Oceanography Centre (NOC) - Liverpool. " Developed by National Centres for Environmental Prediction (NCEP).

common UK-wide forecast dataset provided by the Met Office. Thus, central to the system is a family of numerical weather prediction models that analyse and forecast surface pressure, wind, astronomical tide, surge and wave parameters critical to determining the flood risk. The models run by the Met Office in support of UK coastal forecasting at January 2011 are listed in Table 1.

For a finite computing resource, a dilemma exists between the necessity to capture intense far-field effects requiring wide area modelling, the need for a high degree of resolution at the coastline in order to represent accurately details of topography/bathymetry and using potentially more expensive models in order to incorporate extra physical processes in shallow water. The domains and resolutions given in Table 1 show that the current suite of Met Office models concentrates on representing offshore conditions correctly. The principal reason for this is that high waves and surges are generated as a result of strong winds blowing over large areas of sea, and without this information, a standalone coastal model would be of limited value. However, a second concern is that, at coastal scales and in shallow water, a number of physical processes become dominant that have not been historically well captured through numerical hindcast/forecast modelling. Wave refraction, shoaling, white-capping, bed friction losses and depth-limited breaking may now be modelled reasonably well by the present generation of phase averaging spectral wave models, following considerable research effort resulting in codes such as SWAN (Booij et al., 1999) and TOMAWAC (Benoit et al., 1996). However, reflection from steep shorelines or structures also occurs in reality, with associated overtopping, erosion, breaching and inundation requiring specialist modelling. These aspects are not yet effectively integrated with larger scale tide, surge and phase-averaged wave models, and we address some of these aspects here.

The present compromise in modelling presents a major challenge for forecasters because they are provided with data to which some confidence can be attributed at locations 
several kilometres offshore from the coast (typically order $10 \mathrm{~km}$ ), but a significant knowledge gap has then to be bridged in order to issue a warning based on the likely shoreline and inland impacts. The EA regions have adopted a number of different methods to deal with this issue, often including the use of additional downscaling models and empirical formulae in order to determine the likely risk of overtopping at specific locations, e.g. Lane et al. (2009). However, for all the methods used, it is judged that the uncertainties associated with forecasts offshore may be significantly amplified in the final shoreline forecast because of the limited evidence base from which the methods are derived. As a result, there is a need both to supplement the observational evidence underpinning empirical formulae and coastal forecasting practices through process modelling and/or data analysis, including correlation analysis, and to engineer the new results into a consistent operational forecasting system. As computer processing power increases and more data become available, the capability to meet operational resource requirements is likely to be met. The present challenge is to integrate models to give the best representation of coastal tide, surge, wave and inundation processes.

\section{Offshore wind waves and surge}

At the largest scales in the ocean, there are models for the offshore processes involving wind waves and storm surges. Essentially, both processes are driven by the atmospheric mesoscale (Figure 4). Surface pressure analyses during both the 2007 Walcott flooding event (Horsburgh et al., 2008) and the catastrophic 1953 North Sea flood event (Wolf and Flather, 2005) show mid-latitude depressions that are broadly similar. There are differences in the detail, however: the paths of the central pressure minima were different, and the 1953 event had stronger winds, with a larger onshore component.

Since the 1953 event, major advances have been made in the operational forecasting of weather and storm surges. A UK National Tide Gauge Network of 44 coastal tide gauges constrains the tide and surge model forecasts, and data assimilation and ensemble forecasting systems have been implemented to improve weather forecasts. Coastal flood defences have been vastly improved to protect the UK from extreme events. However, the challenge of improving coastal flood prediction depends on continued progress on constraining the forecast uncertainty in the integrated models from the atmospheric mesoscale $(\sim 1000 \mathrm{~km})$, to offshore wind waves and surges $(\sim 1000 \mathrm{~km}$ to $\sim$ few $\mathrm{km})$, to nearshore waves and water levels and right down to inundation models $[\mathrm{O}(1 \mathrm{~m})]$.

Surges are forced by winds and also atmospheric pressure (the inverse barometer effect). Winds are only significant in surge generation over the continental shelf in relatively shallow depths. Waves, on the other hand, are forced by winds alone. The effective wind forcing parameters are wind speed, duration and fetch. Wind speed and fetch (especially fetch) are larger over the open ocean where waves are not dissipated by bottom friction or shoaling; thus, large waves can propagate from the ocean onto the continental shelf.

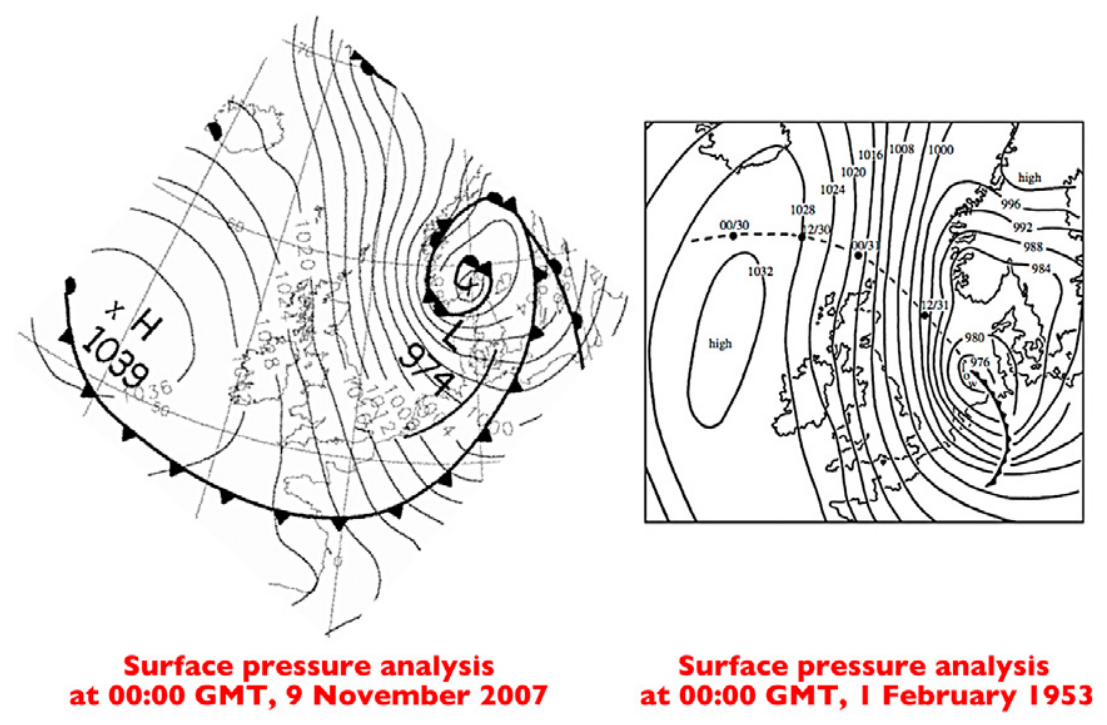

from Horsburgh et al. (2008)

from Wolf and Flather (2005)

Figure 4 Surface atmospheric pressure analyses (mbar) adapted from Horsburgh et al. (2008) and Wolf and Flather (2005) for the flood events of 2007 and 1953. 
Wave boundary conditions must be supplied for a regional wave model, whereas the surge model only needs to cover the continental shelf. Over the ocean, global atmospheric models are generally not of as high resolution as over regional seas. This can lead to an underestimation of peak storm winds and hence wave heights (Caires and Sterl, 2005). On the other hand, the extent of the fetch may be limited in a regional model so that the waves are not fetch limited; e.g. for strong northerly winds in the North Sea, the fetch may extend into the Arctic, although the fetch may also be limited by ice cover (Wolf and Woolf, 2006). These issues need to be considered in wave hindcasting (Cavaleri, 2009).

The coupled hydrodynamics-wave system Proudman Oceanographic Laboratory Coastal Ocean Modelling System-Wave Model (POLCOMS-WAM) has been under development at the NOC, Liverpool, for the last 10 years (starting with Wolf et al., 2002). Wolf (2008, 2009) discusses the development of such coupled wave and surge models, and the coupling between the POLCOMS and WAM is described in detail by Osuna and Wolf (2005). This model system has been implemented for the north-west European shelf region on a computational domain extending from $48-63^{\circ} \mathrm{N}$ and $12^{\circ} \mathrm{W}$ to $13^{\circ} \mathrm{E}$, with resolution $1 / 9^{\circ}$ latitude by $1 / 6^{\circ}$ longitude (approximately $12 \times 12 \mathrm{~km}$ ). It was used to hindcast the Walcott surge and wave event for November 2007. The hydrodynamic model, POLCOMS, as described in Holt and James (2001), was used to provide the timeevolving tide and surge conditions. The wave model component, WAM, works as a module of POLCOMS, so the wave model uses the same bathymetry and wind information supplied to the hydrodynamic model.

The wave model is a version of the third-generation spectral WAM (Komen et al., 1994), which has been extended to be applicable at continental shelf scale in shallow water (Monbaliu et al., 2000). For this application, the wave model does not take into account the effect of interaction between waves, water level and currents, although this option is available and may be important in very high-resolution nearshore regions (Brown et al., 2011). Here, this coastal domain is modelled separately with boundary conditions from POLCOMS-WAM.

The model was forced by UK Met Office mesoscale $(\sim 12 \mathrm{~km})$ atmospheric model winds and pressures, while wave boundary conditions were obtained from a previous coarser implementation of POLCOMS-WAM for the northeast Atlantic $\left(1^{\circ} \times 1^{\circ}\right.$ resolution, extending from $40-70^{\circ} \mathrm{N}$ and $25^{\circ} \mathrm{W}$ to $15^{\circ} \mathrm{E}$ ), forced by winds from the European Centre for Medium-Range Weather Forecasting model. In both model implementations, the wave model spectral resolution was 24 directions and 25 frequencies. The wave bottom friction was specified according to Madsen et al. (1988). WAM computes the evolution of the 2D (frequencydirection) wave spectra, which are then used to estimate the

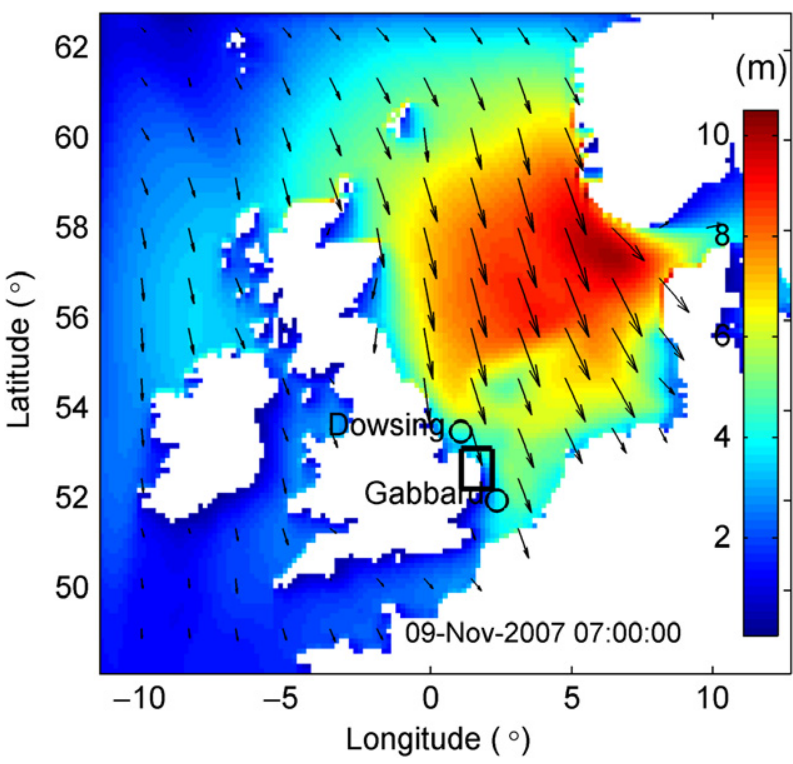

Figure 5 Significant wave height from the wave model (WAM) at 07:00 on 9 November 2007. The arrows show the mean wave direction at that time. The black rectangle shows the location of the coastal domain. The two circles show the location of wave buoys at Dowsing and Gabbard.

value of a number of integrated parameters (e.g. significant wave height, mean wave direction, zero-crossing wave period) at every point of the computational domain.

POLCOMS-WAM has been validated on an Irish Sea domain extending from $7^{\circ}$ to $2^{\circ} \mathrm{W}$ and $51^{\circ}$ to $56^{\circ} \mathrm{N}$ with $176 \times 301$ grid cells and a resolution of $1 / 40^{\circ} \times 1 / 60^{\circ}$, a variable resolution of around $1.8 \mathrm{~km}$, by Brown et al. (2010). This showed that POLCOMS does not have a systematic bias in water level, whereas WAM consistently underpredicts the wave height across the region. This underprediction could be related to the boundary forcing errors in wind or the surface drag coefficient. However, the model root mean square errors are generally within acceptable limits. Another aspect of the air-sea coupling is addressed by Brown and Wolf (2009), which shows how the surface wind-stress drag coefficient may vary with wave age, but this has not been implemented for this application. Further work is in progress on fetch-limited wave growth in enclosed seas which is often underestimated in wave models (e.g. Cavaleri, 2009).

Figure 5 shows the significant wave height over the continental shelf model for the time of maximum wave height just offshore of Walcott, at 07:00 on 9 November 2007. The wave height reached about $4 \mathrm{~m}$ within a few kilometres of the shore.

Figure 6 presents the significant wave heights at two locations both computed by the wave model and measured at two wave buoys located at Dowsing and Gabbard (see Figure 5). As already stated, the model underestimates the wave height for the event that took place on 9 November. 

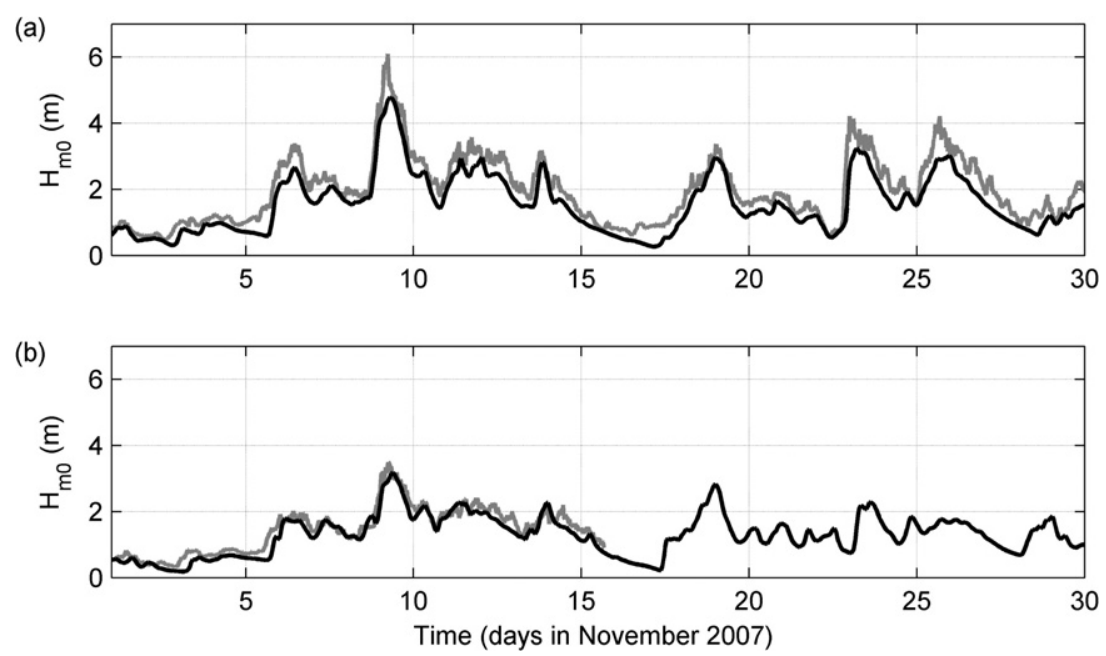

Figure 6 Significant wave height at Dowsing (a) and Gabbard (b). At each location, model output and buoy measurements are respectively represented by the black line and the grey line.

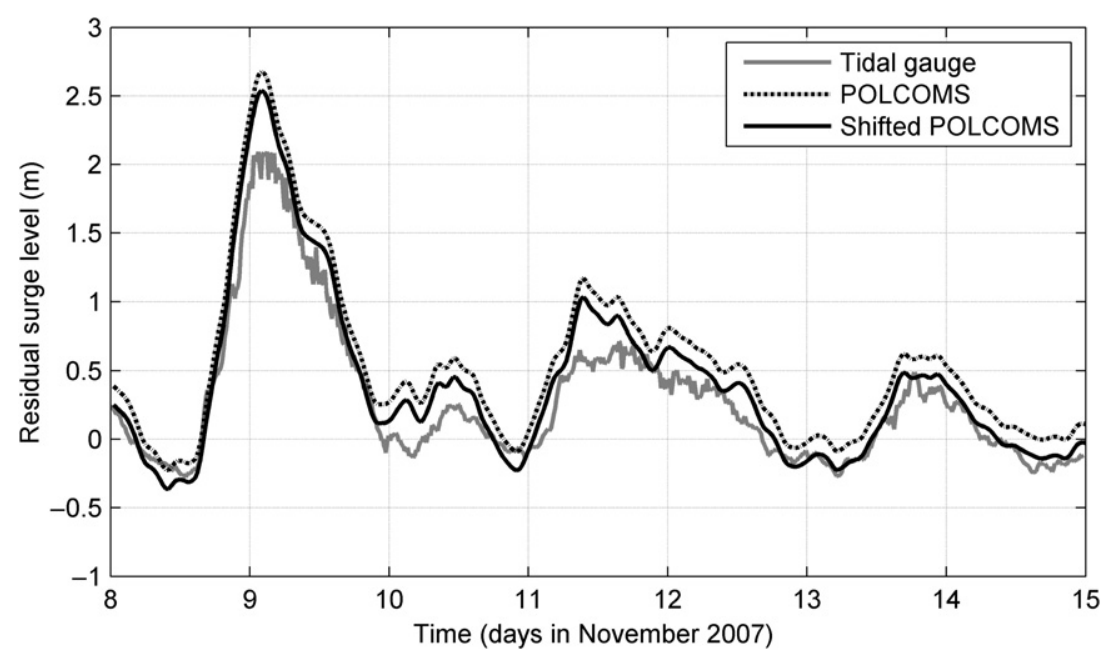

Figure 7 Residual surge from model and observations from Lowestoft. Horizontal axis is date for November 2007. Vertical axis is surface elevation in metres. The model grid cell used to represent Lowestoft was at 52.4776 degrees N, 1.7584 degrees E.

Figure 7 shows the surge elevation from the POLCOMS model compared with the tide gauge data for Lowestoft, the nearest reliable coastal tide gauge (to the south of Walcott as shown in Figure 1). In the case of the 'shifted' line, the total water level has been corrected by subtracting the difference between the tidal mean water level for the model and observations (i.e. a datum shift), which brings the model into closer agreement with the observations. This correction was $0.14 \mathrm{~m}$ at Lowestoft.

Sources of forecast uncertainty for surges and waves are due to (1) the chaotic nature of the atmosphere and ocean, combined with (2) imperfect knowledge of the initial state of the system becuase of small errors or sparseness in observations, (3) imperfect knowledge of the future external forcing of the system at its boundaries and (4) imperfect description of the evolution of the system by the physical equations used in computer forecast models. As is demonstrated in weather forecasting, there are certain situations when the chaotic nature of the system reduces the forecast accuracy and other times when all the likely forecast states cluster around the same outcome. Similar behaviour is possible in the individual models linking the mesoscale to the small scale, so forecast uncertainty in one model may propagate to the other models as uncertainty in their boundary conditions.

Both the wave and the surge from POLCOMS-WAM provide boundary conditions for the nearshore wave and water level models - the next level down in the integrated model framework. 


\section{Nearshore waves and water level}

Waves generated offshore and approaching the nearshore are influenced by shallow water depths and varying bathymetry, leading to shoaling, refraction and loss of energy either due to bottom friction and/or due to wave breaking. Off Walcott, the tidal and surge water levels are large enough to interact with wave propagation. To simulate all these physical processes, the TELEMAC suite (Hervouet, 2007), containing a shallow water hydrodynamic solver and a wave action conservation equation solver, was set up to model inshore water levels and wave spectra for November 2007. This open-source system was chosen because it allows fine mesh resolution when needed through the finite element (FE) mesh. A one-way nesting procedure with POLCOMS-WAM was implemented, where the output from the coarser model was used to drive the finer model.

\section{TELEMAC computational grid}

The grid consists of 5506 triangular elements of variable size. A coarse resolution of $2400 \mathrm{~m}$ (the side length of approximately equilateral triangles) was applied where the bathymetry was deeper than $25 \mathrm{~m}$ Ordnance Datum Newlyn (ODN). To capture the presence of sandbanks and nearshore seabed profiles, a finer resolution of $700 \mathrm{~m}$ was used. The bathymetry from a 2002 survey, provided under licence by Seazone Ltd, is referenced to the Chart Datum. This reference datum has been modified to be consistent with POLCOMS outputs which have water level referenced to the mean sea level. The same computational grid was used for waves and tide-surge propagation.

\section{The nesting procedure}

The TELEMAC grid was embedded within the POLCOMS grid, and outputs from POLCOMS were imposed along the boundary of the TELEMAC computational domain. Because the resolutions of the TELEMAC and POLCOMS grids differ, bilinear spatial interpolation was applied to POLCOMS outputs in order to estimate, at each TELEMAC boundary node, either the water levels and the velocity components or the wave parameters. Linear interpolation was also applied to define the temporal evolution of boundary conditions. Along the coastline, a slip condition was used. A uniform bottom friction coefficient was specified based on the Nikuradse equivalent bottom roughness. A roughness length of $0.0011 \mathrm{~m}$ was used, representative of sand with a median grain size of $450 \mu \mathrm{m}$ according to the formula $k_{s}=2.5 D_{50}$ (Soulsby, 1997), where $k_{s}$ is the Nikuradse roughness length and $\mathrm{D}_{50}$ the median grain size.

\section{Inshore water levels}

Figure 8 shows that the nested model predicts very similar water levels to POLCOMS offshore of Lowestoft where there is a tide gauge for comparison. The model results slightly overestimate the tide gauge measurements by up to $0.2 \mathrm{~m}$ during the storm but more on other occasions. This compares with an overprediction of surge level of up to $0.5 \mathrm{~m}$ shown in Figure 7. There is thus some error in tide level as well as surge level. At Walcott, a hindcast simulation provided estimates of the maximum water levels that occurred during the night between 8 and 9 November 2007 and the duration of the event. For this particular event, the

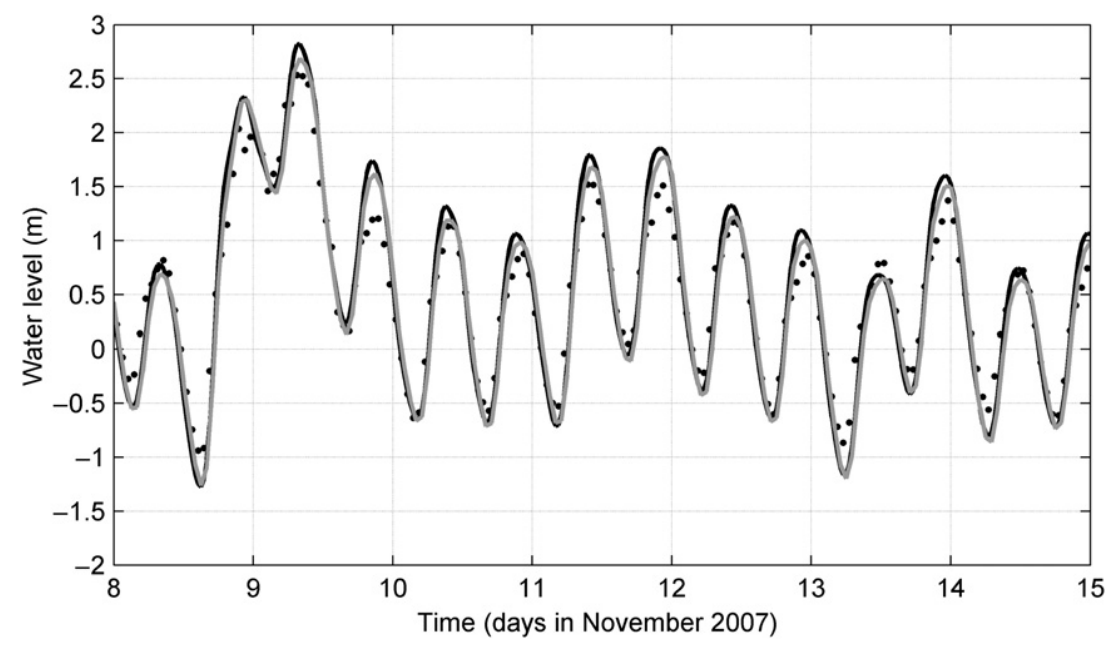

Figure 8 Water level at Lowestoft. Dots are the measurements at the tidal gauge. Black line is Proudman Oceanographic Laboratory Coastal Ocean Modelling System (POLCOMS) output and grey line is TELEMAC output. 
maximum water level predicted by POLCOMS at Walcott is $3.08 \mathrm{~m} \mathrm{ODN}$ at $7 \mathrm{am}$ on 9 November.

\section{Inshore wave propagation}

To represent the physical processes influencing inshore wave propagation, a numerical approach was adopted based on the third-generation wave model, TOMAWAC (Benoit et al., 1996). The model takes into account bathymetric wave breaking, bottom friction, non-linear wave-wave interactions, wind wave generation and white-capping. Kuang and Stansby (2004) showed that TOMAWAC is able to represent the spread wave fields induced by the presence of sandbanks in this region. Further details about model parameterisation and model validation are given by Chini et al. (2010).

Offshore waves extracted from POLCOMS-WAM every hour were propagated towards the nearshore using the model in the one-way nesting procedure. The model was then used to produce integrated wave parameters and directional wave spectra at a nearshore location $1 \mathrm{~km}$ off Walcott, where the water depth is $-12 \mathrm{~m}$ ODN.

Inclusion of wind effects is necessary for storm conditions (Kuang and Stansby, 2004). Wind data were provided by the Met Office from the hindcast of November 2007.

For the 2007 event, a sensitivity test has been undertaken on the choice of boundary condition for the wave forcing. Three different conditions were considered: a uniform boundary condition with a single set of integrated wave parameters around the boundary and two non-uniform boundary conditions, using either spatially interpolated wave parameters or spatially interpolated wave spectra. Figure 9 shows the sensitivity of the model to these boundary conditions. It appears that the three boundary conditions produce very similar estimates for the peak of the storm, with the discrepancy in significant wave height below $0.1 \mathrm{~m}$.

\section{Beach levels}

Many coastal structures rely on the presence of a healthy beach in order to guarantee their designed performance. A key element in the performance is the extent to which wave energy can penetrate up the beach to the structure. Wave energy is rapidly dissipated through the process of breaking. At the shoreline, waves break primarily as a result of the reducing water depth, which causes the waves to become more asymmetric in profile. The crucial parameter is the water depth, which depends upon the beach elevation and the water level (due to tides, surge and setup). To predict the possible range of water depths requires predictions of the beach topography. From this perspective, it is necessary to understand how sea walls and beaches interact during storms.

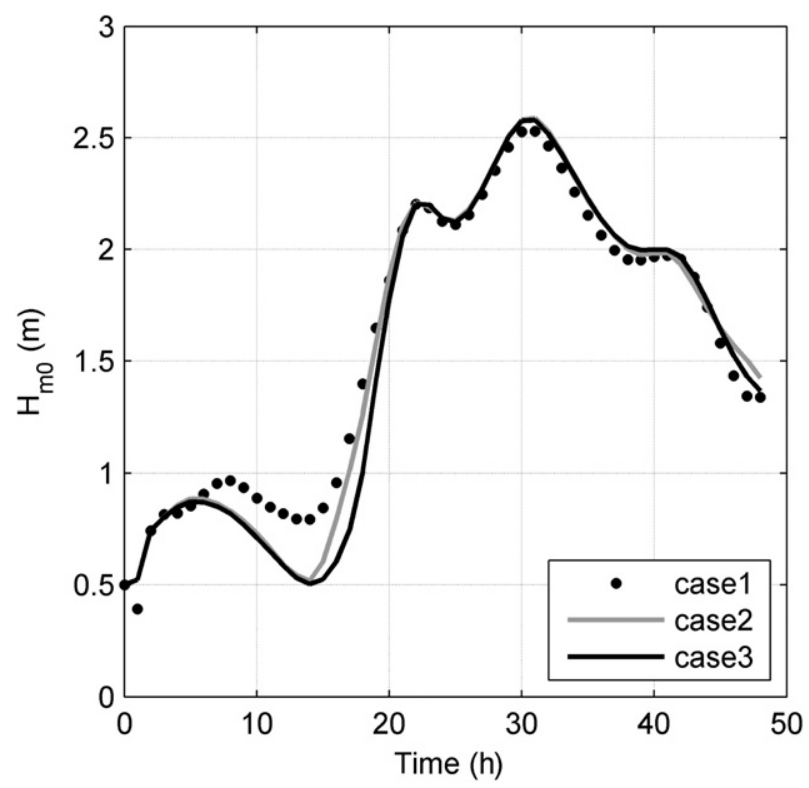

Figure 9 Significant wave height off Walcott. Sensitivity to offshore boundary conditions. Case 1: uniform boundary condition. Case 2: non-uniform boundary condition using integrated wave parameters. Case 3: same as Case 2 but using the wave spectrum. Time $\mathrm{t}=0$ corresponds to 00.00 on 8 November 2007 .

Beach prediction models come in essentially three forms: (1) formulae that describe an equilibrium shape as a result of fixed wave conditions (e.g. Dean et al., 1993); (2) detailed process models that can provide good results over the period of a storm but have difficulties in terms of accuracy and stability for longer-term predictions; and (3) datadriven models that rely on a statistical analysis of historical records and extrapolation to forecast future conditions (e.g. Różyński, 2003). Here, we follow the latter method using the canonical correlation analysis (CCA) to relate beach profiles to the incident wave conditions. The CCA identifies covariability patterns for coincident random fields, such as beach level and wave height. It provides what is essentially a regression relationship between the two sequences, which can be used as the basis for predicting one variable from the other.

The CCA was originally proposed by Hotelling (1936), who was interested in investigating the correlation between two sets of variables. The mathematical details of the CCA are given by Clark (1975) and Graham et al. (1987). In brief, if we have two sequences of data, $Y$ and $Z$, say, then the CCA algorithm produces a regression matrix $A$ such that $Z=Y A$, using matrix multiplication. Much of the difficulty in application arises in choosing the most effective sequences of data. In the present case, one of the data sequences comprises measured beach profiles, which form the rows of matrix $\mathrm{Z}$. The other sequence needs to be a function of one variable 


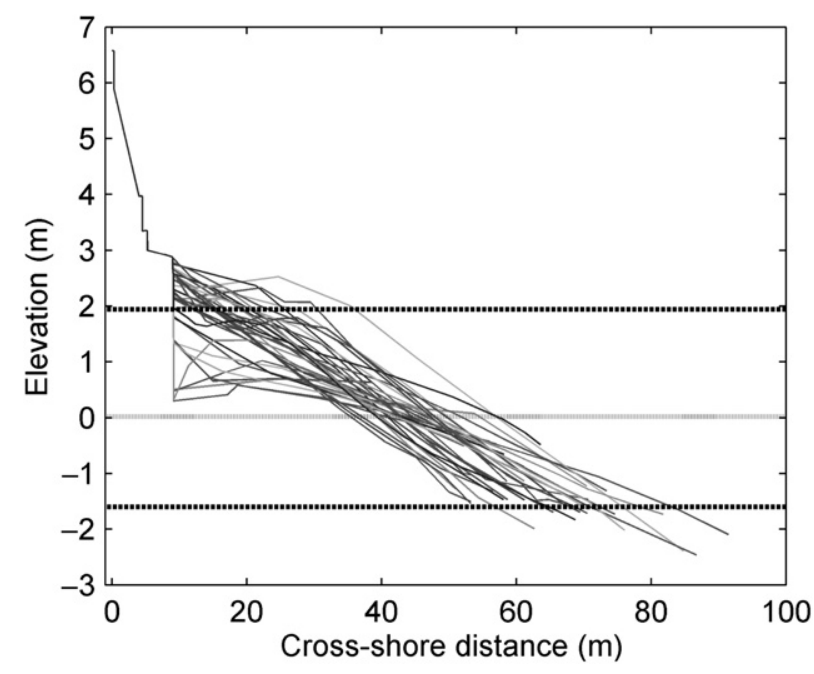

Figure 10 Composite plots of beach level measurements [relative to Ordnance Datum Newlyn (ODN)] taken at Walcott, showing the hard defence at the top of the sloping beach. Heavy dashed lines show mean high water springs (MHWS) and mean low water springs (MLWS) levels.

that describes the wave conditions. A major constraint of the method is that the two sequences must be analysed the same number of times. Here, following Larson et al. (2000), the second sequence comprises measured beach profiles and the probability distribution functions of wave parameters computed from the records between successive beach profile measurements.

The Walcott site is a sandy beach in a meso-tidal environment with a hard structure at the top of the beach. The mixed shingle-sand beaches of Walcott have been monitored since 1991 along 18 shore normal profiles, as part of a long-term beach management survey programme by the North Norfolk District Council (Wallingford, 2002). The surveys were carried out in the summer and winter months. Profile N3C8 has been used for this study as it includes the sea wall. Figure 10 displays the subset of measured profiles along Profile N3C8 (25 profiles shown). Only surveys that extended from the defence out to a water depth of approximately the mean low water level were included in the analysis.

For this application, wave information obtained by hindcasting from wind measurements is standard and sufficient; waves were calculated using winds at Weybourne, UK $\left(52^{\circ} 51^{\prime} 0.25^{\prime \prime} \mathrm{N}, 1^{\circ} 30^{\prime} 59.40^{\prime \prime} \mathrm{E}\right)$, using the CERC formulae (USACE, 1984). Independent wave predictions provided by the EA were used to validate the wave hindcasts. The wave dataset available for this area consists of hourly values of significant wave height $\left(H_{m 0}\right)$, peak spectral wave period $\left(T_{p}\right)$ and wave direction $(\theta)$. The hindcasting point is located in approximately $12 \mathrm{~m}$ water depth and $1.3 \mathrm{~km}$ offshore. The predominant wave directions are from the north, north-east and east, and the largest surges are associated with winds from the north-west and the north. The tidal ranges are 3.54 and $1.72 \mathrm{~m}$ for spring and neap, respectively. Wave conditions obtained from the hindcast were used to calculate the empirical probability density functions for the CCA.

Given that a total of 25 beach profiles were available, the first 15 profiles were used in defining the regression matrix, whereas the subsequent profiles were used for validating predictions made with the regression matrix. Each profile contained many more wave observations than beach profile measurements, and so to generate two series of equal length, as required for the CCA method, the wave conditions were compiled into probability density functions (pdfs) using the empirical distribution suggested by Horrillo-Caraballo and Reeve $(2008,2010)$. (There were about 160000 wave data records over the 17-year period of beach surveying.) The pdfs used here were discretised into about 200 intervals, sufficient to provide a satisfactory resolution over the probability interval of significance. Figure 11 shows a composite plot of the pdfs of the offshore significant wave height and wave steepness.

Two different CCAs were performed (one for each of the wave parameters - significant wave height and wave steepness) using beach profiles, significant wave heights and wave steepness from 12 August 1991 to 1 August 2003 (approximately 25 profiles and 25 empirical pdf distributions) to determine the regression matrices, and then predictions from 19 January 2004 to 15 September 2008 (approximately 10 profiles) were computed using the hindcast wave data.

This enabled investigation of the quality of predictions using different regression matrices (empirical pdfs with significant wave height and wave steepness). In each case, the datasets were prefiltered to reduce noise, following the recommendations by Clark (1975) and North et al. (1982). Details of this process as applied to the Walcott site are given by Horrillo-Caraballo and Reeve (2011). One motivation for the tests was to ascertain how the choice of pdf might affect the quality of predictions. Such information could have direct application in the planning and collection of beach monitoring measurements for coastal management and prediction of the condition (erosion or accretion) of the coastline.

Figure 12 compares the measured profile and predictions made using the regression matrix plus wave information between August 2003 and the date of the beach survey (15 February 2006). Predictions were made from 2003 to all subsequent survey dates. Figure 12 shows typical results. In general, there is not much difference between the predictions using wave heights or wave steepness, although wave heights provide somewhat better predictions further from the structure. Both forecasts tend to underestimate the beach level near the toe of the structure (thereby providing 

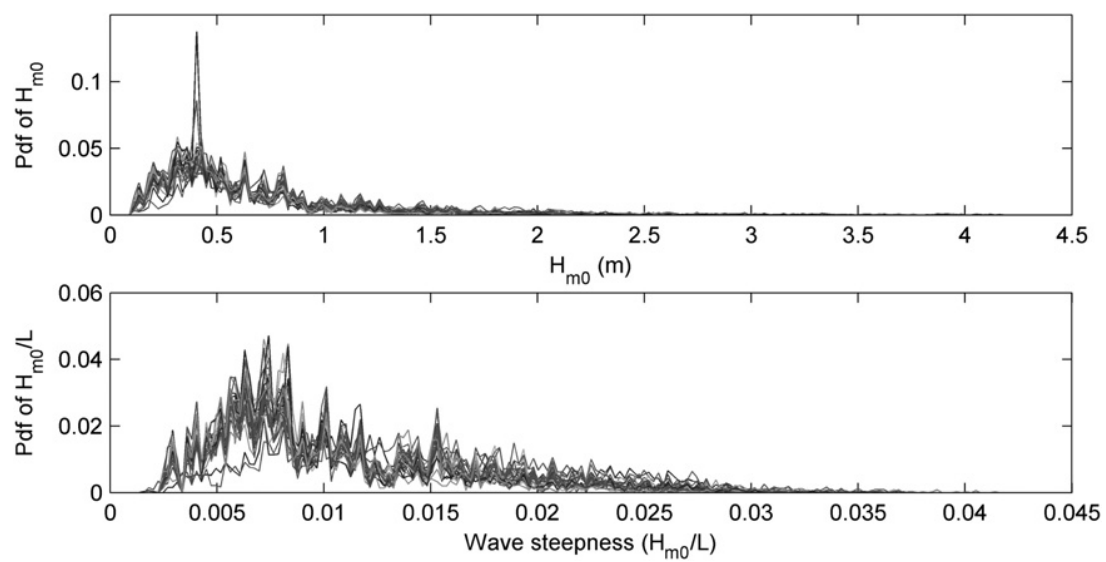

Figure 11 Composite plots of empirical probability density functions (pdfs) of significant wave height (top panel) and time series of empirical pdfs of wave steepness (bottom panel) at Walcott.

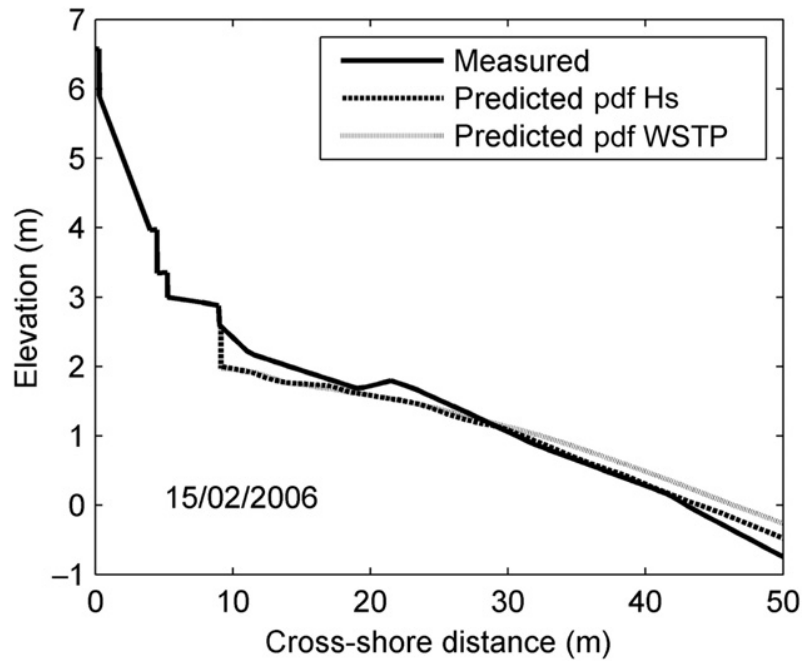

Figure 12 Measured profile for 15 February 2006 and predictions using wave height and wave steepness based on regressions determined from data up to August 2003.

a conservative estimate of beach level for wave overtopping estimates) and overestimate the beach levels seaward of a chainage of about $30 \mathrm{~m}$. Using wave heights, the maximum error in the prediction was less than $0.5 \mathrm{~m}$ across the whole profile, and considerably less than this except near the profile extremities.

Figure 13 shows the predicted beach profile on the day of the storm (9 November 2007). The predictions cannot be validated against measurements for this particular date. However, the predictions suggest that the beach was not at a particularly low level at the time the storm occurred, and therefore provided some protection against wave overtopping in addition to the sea wall. That is, had the beach been as low as has sometimes been recorded, the overtopping could have been much worse.

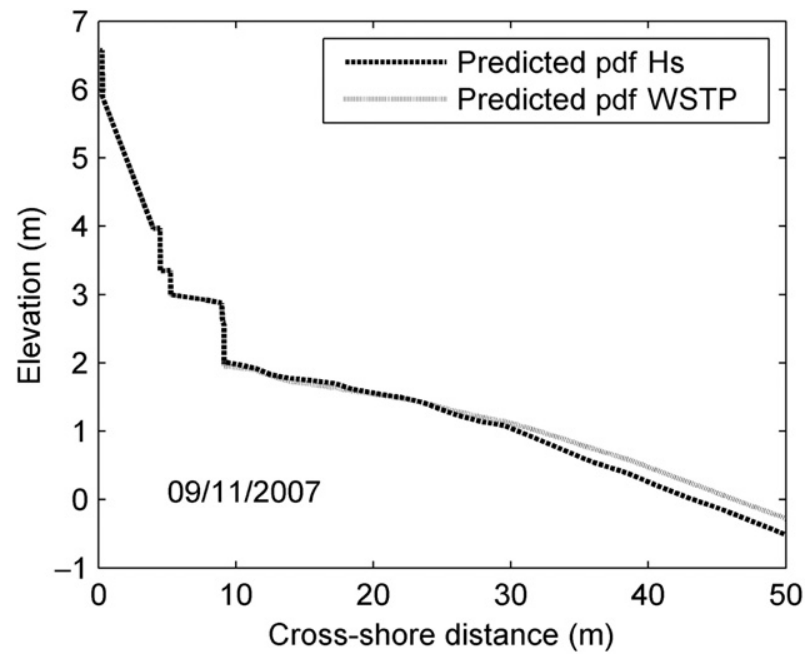

Figure 13 Predicted profile for 9 November 2007 using wave heights and wave steepness.

Figure 14 shows a comparison between the measured profile and predictions made using the regression matrix plus wave information between August 2003 and the date of a beach survey almost 1 year after the storm (15 November 2008). As in Figure 10, there is not much difference in the predictions using wave height or wave steepness, although wave height provides somewhat better predictions further from the structure. Both forecasts tend to underestimate the beach level near the toe of the structure. The measured profile is undulating, indicating the presence of antecedent standing waves created by reflection from the sea wall, (e.g. Sumer and Fredsøe, 2002; DEFRA 2005). The prediction suggests some undulation but fails to capture the height and extent of the bar at $20 \mathrm{~m}$ chainage, although it captures the beach level at the toe of the structure very well. 


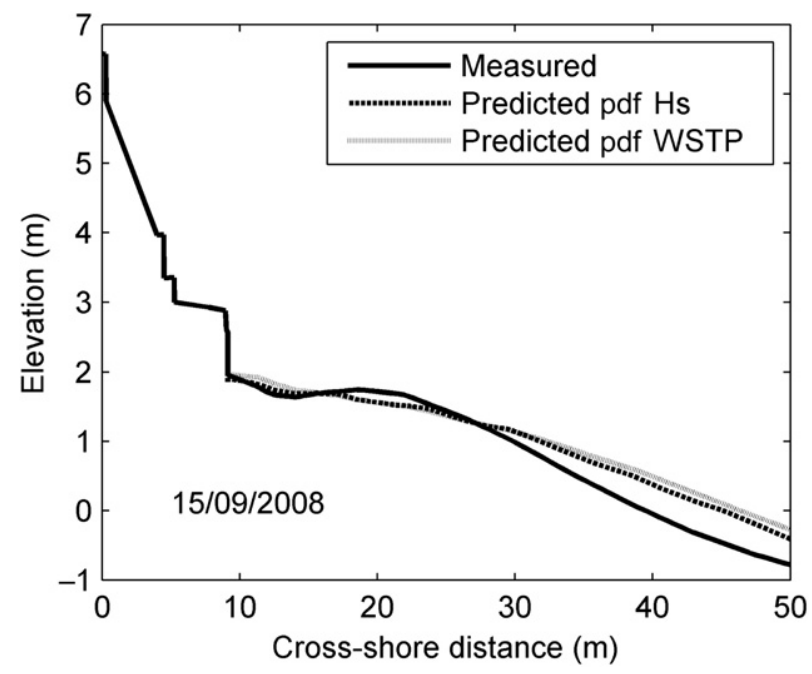

Figure 14 Measured profile for 15 November 2008 and predictions using wave height and wave steepness based on regressions determined from data up to August 2003.

\section{Overtopping}

\section{Overtopping prediction using EurOtop}

The concrete sea wall protecting Walcott is shown in Figure 15. The sea wall consists of a vertical wall, whose top is located $3.0 \mathrm{~m}$ above ODN, followed by a $2.75-\mathrm{m}$ wide horizontal berm; the slope of the structure upward of the berm is $2: 1$. The sea wall crest is at $6.6 \mathrm{~m}$ ODN, with a recurve. Figure 15 shows the sea wall without the recurve, where $h$ is the water level at the toe of the structure. To allow pedestrian access to the beach, stairs are directly constructed within the sea wall. A slipway is also present for launching boats from the coastal road. These two latter features are not represented in the cross-shore section presented in Figure 15.

Several overtopping predictors have been previously developed during the CLASH and EurOtop projects (Pullen et al., 2007; De Rouck et al., 2009). For a sea wall geometry such as Walcott, the neural network approach is recommended (Overtopping Manual; Pullen et al., 2007). An executable of the neural network is available online (http:// www.kennisbank-waterbouw.nl/OvertopComments.htm). The set-up of this network requires 11 different inputs describing the geometry of the sea wall (for further details, see van Gent et al., 2007). These inputs allow representation of a large variety of sea wall geometries. For the sea wall at Walcott, we considered the toe to be non-existent so that the parameters describing the width of the toe, $\mathrm{Bt}$, and the angle of the slope between the toe and the berm, $\alpha_{u}$, are respectively set to 0 and $90^{\circ}$. Given the range of inputs, the presence of the recurve was not taken into account, and the crest width, GC, is set to zero. Table 2 summarises the parameters

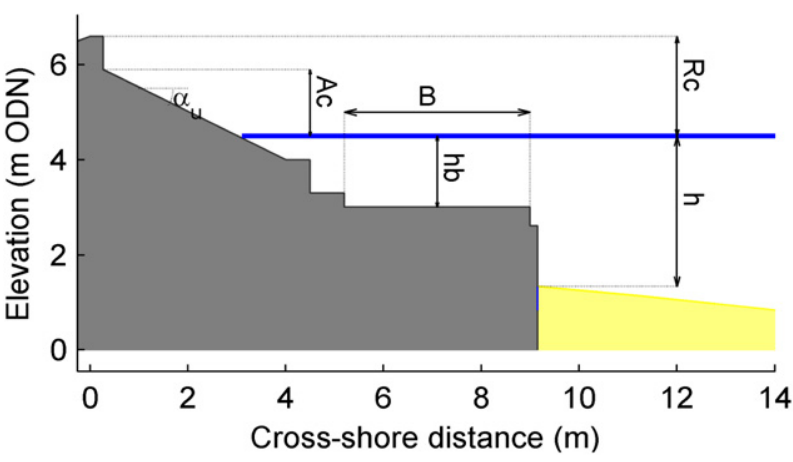

Figure 15 Sketch of sea wall at Walcott.

describing the sea wall according to the nomenclature adopted by van Gent et al. (2007).

The user also needs to define the hydrodynamic conditions at the toe of the structure, i.e. the significant wave height, the wave period, the mean wave direction and the water level, that would occur without the structure present and without reflection. In order to estimate the wave parameters, the Overtopping Manual recommends the use of a spectral model such as SWAN (Booij et al., 1999). Here, TOMAWAC (Benoit et al., 1996), solving the same wave action conservation equation as SWAN but with an FE method, was used with a local computational domain including the foreshore and the sea wall. The unstructured grid contained 8176 points and 16032 triangular elements. The spatial resolution varied from $0.1 \mathrm{~m}$ along the coastline to $80 \mathrm{~m}$ offshore. The bathymetry was assumed uniform alongshore. The profile surveyed in summer 2007, just prior to the November 2007 event, was used as input for the bathymetry of the model. The spectral frequency and directional resolution were set to 25 frequencies, with a minimum frequency of $0.042 \mathrm{~Hz}$, and 24 directions. The Joint North Sea Wave Project bottom friction coefficient of $0.038 \mathrm{~m}^{2} / \mathrm{s}^{3}$ (Hasselmann et al., 1973) and the formulation for depth-induced wave breaking of Battjes and Janssen (1978) were used. The time step was set to $2 \mathrm{~s}$. Along the coastline, a closed boundary was imposed. The wave spectrum computed in the fourth section was imposed along the offshore boundary. To allow any incoming wave direction, the wave spectrum along any point on the lateral boundaries was set to be equal to the spectrum of the closest interior point. Dry areas were represented by a small water depth over which there was no wave propagation. In order to include the wave set-up effect, the formula of Dean and Dalrymple (2002) for regular waves is applied and the term $h_{s}=0.19 H_{b}$ is added to water depth at the toe of the structure, where $H_{b}$ is the breaker height. This only gives an approximate value; for example, Guza and Thornton (1981) suggested a representative formula $h_{s}=0.17 H_{s b}$ with quite a wide variation based on field measurements. Significant 
Table 2 Neural network inputs: coastal structure geometry parameters

\begin{tabular}{lcccccccccc}
\hline $\mathrm{Ht}(\mathrm{m})$ & $\mathrm{Bt}(\mathrm{m})$ & $\cot \alpha_{d}$ & $\cot \alpha_{u}$ & $\mathrm{Rc}(\mathrm{m})$ & $\mathrm{B}(\mathrm{m})$ & $\mathrm{hb}(\mathrm{m})$ & $\alpha_{\mathrm{b}}$ & $\mathrm{Ac}(\mathrm{m})$ & $\mathrm{GC}(\mathrm{m})$ & $\gamma_{f}$ \\
\hline $\mathrm{h}$ & 0 & 0 & 1.78 & $6.6-\mathrm{h}$ & 3.72 & $\mathrm{~h}-3$ & 0 & $5.9-\mathrm{h}$ & 0 & 1 \\
\hline
\end{tabular}

wave height, wave period, $\left(T_{m-1}\right)$ and mean wave direction were extracted at the toe of the structure and then used as input to the EurOtop neural network. For the given hydrodynamic conditions and the geometry of the coastal structure, the neural network returns the mean overtopping discharge rate and $2.5 \%, 5 \%, 25 \%, 50 \%, 75 \%, 95 \%$ and 97.5\% quantiles of overtopping discharges.

The coupling between TOMAWAC and the EurOtop neural network was driven by the hourly wave spectra and water levels from the models presented in the fourth section for the November 2007 event.

\section{Overtopping prediction using shallow-water and Boussinesq (SWAB) modelling}

Shallow-water models with the hydrostatic pressure assumption are widely used for coastal flow modelling, including inundation. Boussinesq models are essentially an extension with additional terms accounting for frequency dispersion effects through perturbation analysis; physically, the hydrostatic pressure assumption is relaxed with the nonhydrostatic pressure approximated. Here, we used the welltried formulation of Madsen and Sørensen (1992), which is robust and gives quite accurate wave propagation for $\mathrm{kh}<3$, where $\mathrm{k}$ is the wave number and $\mathrm{h}$ is the local depth. The shallow-water equations with additional Boussinesq terms were solved following Stansby (2003). Offshore boundary conditions were implemented by the method of Larsen and Dancy (1983), where the surface elevation time history is input within the computational domain generating waves propagating offshore and inshore; no intermediary paddle motion is required as in other approaches. The offshoredirected waves were absorbed by a sponge layer. The onshore-directed waves propagate towards the shore, and waves reflected from the shore propagate offshore through the input location giving an effective radiation boundary condition. Wave breaking is of vital importance, and this complex physical process has to be modelled simplistically within this approach. In the present model, the breaking criterion was based on a limiting value of wave height to local water depth applied to random waves on a wave-bywave basis, following McCabe et al. (2011). At a given time, a wave cycle was defined by adjacent zero upcrossings, and the crest and trough were identified to give a wave height $H$. If $\mathrm{H} / \mathrm{h}>0.6$, the Boussinesq terms were simply switched off. This was tested against experiments for the overtopping of the sea wall at Anchorsholme, Blackpool, similar to that at Walcott, and proved remarkably effective in predicting inshore wave characteristics and overtopping volumes (McCabe, 2011). In order to model the effect of the recurve, an opposing force was applied that is proportional to the momentum flux over the height of the recurve. A proportional constant of unity proved effective that is equivalent to the flux being ejected vertically, which was roughly consistent with observation. This formulation was also applied here, with input wave data from a position $0.8 \mathrm{~km}$ offshore, the limit of the beach survey, shown in Figure 16. This surveyed profile was used as the bathymetry for the SWAB model. The TOMAWAC directional spectra provided the input surface elevation time history for $12 \mathrm{~h}$ of the Walcott storm, with the central $5 \mathrm{~h}$ being used for the SWAB modelling. The directional spectra were integrated to give a spectrum for the 1D model. Note that the nearest node on the TOMAWAC mesh was $1.3 \mathrm{~km}$ offshore (see Figure 16). The bed levels at 1.3 and $0.8 \mathrm{~km}$ were similar at $-13.9 \mathrm{~m}$ ODN and $-12.66 \mathrm{~m} \mathrm{ODN}$, respectively, and the wave spectrum was assumed to be unchanged for input at $0.8 \mathrm{~km}$ offshore. The overtopping time history is shown in Figure 17.

\section{Comparison between EurOtop and SWAB predictions}

The time series presented in Figure 17 was integrated in order to produce hourly mean overtopping discharge rates. These rates are compared with EurOtop predictions in Figure 18. Discharge rates obtained using EurOtop with and without wave set-up are also compared. Inclusion of wave set-up increased the mean overtopping discharge rates predicted by EurOtop by about 30\%. Overtopping is estimated to occur for $4 \mathrm{~h}$ during the highest part of the tidal cycle. Maximum mean overtopping rates occurred during high tide. During the lowest part of the tidal cycle, no overtopping events were predicted.

\section{Inundation}

\section{Terrain elevation model}

The ground elevation of the Walcott surroundings had been measured using light detection and ranging for the EA. This remote-sensing procedure allowed the terrain elevation to 


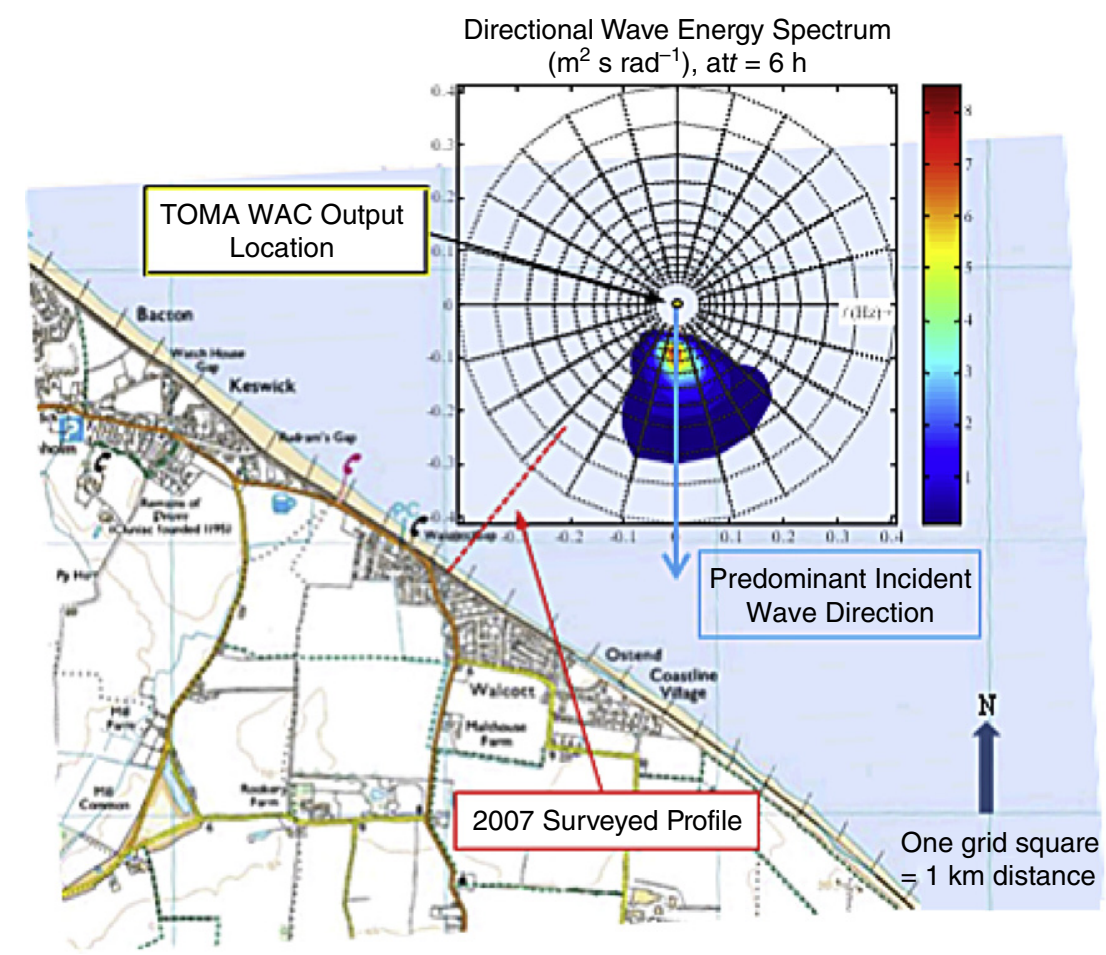

Figure 16 Directional wave energy spectrum at peak of storm, with locations marked.

(a)

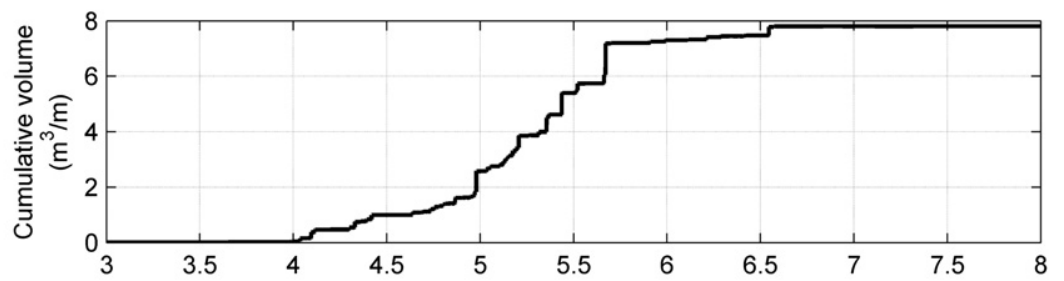

(b)

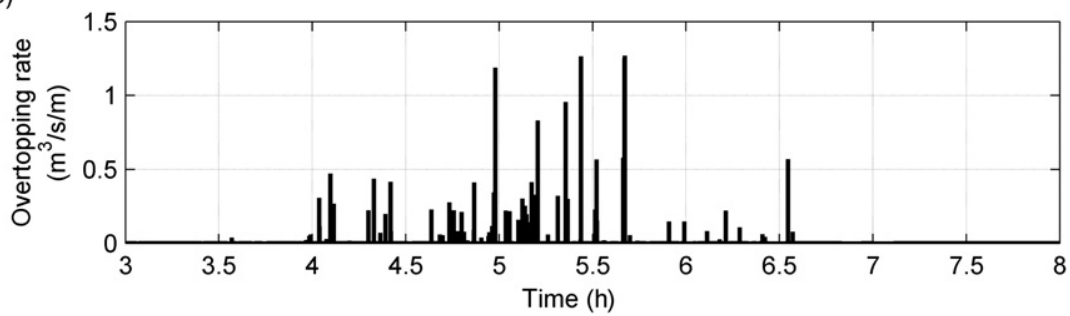

Figure 17 Cumulative overtopping volume (a) and time series of overtopping rates (b) from shallow-water Boussinesq (SWAB) modelling.

be mapped, producing digital surface models (DSMs) at various spatial resolutions. Data, provided by the EA, were at three different resolutions: a coarse resolution of $2 \mathrm{~m}$, an intermediate resolution of $1 \mathrm{~m}$ and a fine resolution of $0.25 \mathrm{~m}$. The spatial extent of the $1-$ and $0.25-\mathrm{m}$ resolution DSM did not cover the entire Walcott community, and so they are not considered here.
The remote-sensing procedure captures objects, such as vehicles or vegetation, that are irrelevant for flood modelling. A filtering procedure is therefore required to assess the presence of such objects and then their removal prior to setting up the flood model (Yan, 2010). Solid blocks with vertical walls are included to represent distinct features, such as houses. The use of solid blocks (see, e.g. Soares-Frazão and 


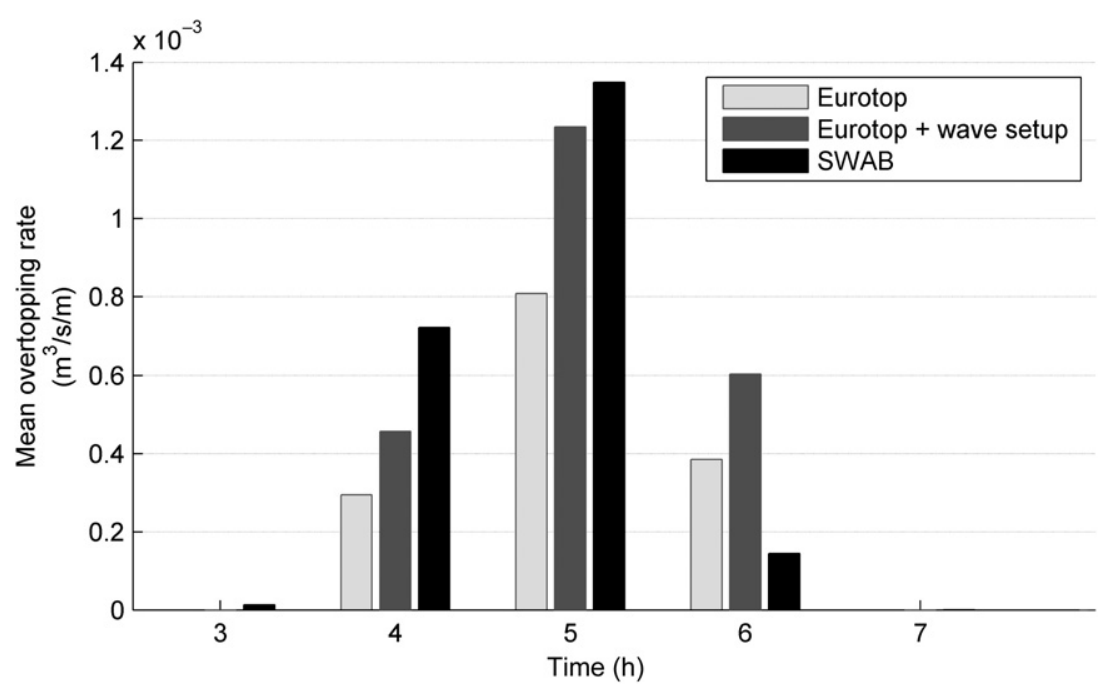

Figure 18 Mean overtopping rates for Walcott storm: shallow-water Boussinesq (SWAB) modelling compared with EurOtop Neural Network results.

Zech, 2008; Jiang et al., 2011) to represent buildings is more accurate than the use of bed roughness or porosity, which do not account properly for the channelling behaviour of the flood wave in urban areas (for a useful comparison, see Liang et al., 2007). Solid blocks were digitised pixel by pixel manually according to the Ordnance Survey, UK Landplan map. Noisy (or wild) values in the raw terrain dataset were identified by means of the terrain elevation gradient,

$$
\vartheta=\sqrt{\begin{array}{c}
n_{\mathrm{N}}\left(z_{\mathrm{b}}-z_{\mathrm{bN}}\right)^{2}+n_{\mathrm{S}}\left(z_{\mathrm{b}}-z_{\mathrm{bS}}\right)^{2}+n_{\mathrm{E}}\left(z_{\mathrm{b}}-z_{\mathrm{bE}}\right)^{2} \\
+n_{\mathrm{W}}\left(z_{\mathrm{b}}-z_{\mathrm{bW}}\right)^{2}
\end{array}}
$$

where $z_{\mathrm{b}}$ is the bed elevation above a fixed horizontal datum of the data point being checked and $z_{\mathrm{bN}}, z_{\mathrm{bS}}, \mathrm{z}_{\mathrm{bE}}$ and $\mathrm{z}_{\mathrm{bW}}$ are the bed elevations of the north, south, east and west neighbour data points. The weightings $n_{\mathrm{N}}, n_{\mathrm{S}}, n_{\mathrm{E}}$ and $n_{\mathrm{W}}$ were determined by trial and error. The terrain elevation values of noisy points were replaced using linear interpolation by

$z_{\text {bnew }}=(1-\alpha) z_{\mathrm{b}}+\frac{1}{4} \alpha\left(n_{\mathrm{N}} z_{\mathrm{bN}}+n_{\mathrm{S}} z_{\mathrm{bS}}+n_{\mathrm{E}} z_{\mathrm{bE}}+n_{\mathrm{W}} z_{\mathrm{bW}}\right)$

where $\alpha$ is again case dependent and is set to 0.8 in the majority of cases. Initially, effort was made to filter the data using Eqns (1) and (2) automatically. Although the procedure worked well for single wild points in a section of terrain with smoothly varying elevation, it did not work effectively for cases involving clusters of wild points because the elevation gradients and interpolations were affected by neighbouring wild points. This problem was more severe when the wild point(s) were located in areas containing complex terrain features. As a result, the following manual piecewise filtering procedure was adopted. A three-dimensonal surface plot of the Walcott area was first generated from the XYZ raster data file and checked visually to determine likely loca- tions of wild points. The bed elevation of each potential wild point and its surrounding area were then assessed using Eqn (1), and, if required, the terrain data were processed using Eqn (2) with case-by-case criteria and weighting values. Wild point identification and replacement were repeatedly carried out in certain complicated areas until all wild points had been removed. Although the manual removal of the noise data points was time consuming, it nevertheless ensured the processed terrain data were of high quality. Figure 19 presents the filtered digital terrain model and the location of the blocks used in the numerical modelling.

The computational domain includes the most densely populated residential area of Walcott and a low-lying coastal region to the north-west of the domain, both of which are vulnerable to inundation from direct wave overtopping.

\section{Overtopping flow discharge input}

During storms, wave overtopping occurs intermittently depending on the offshore conditions. The range of overtopping discharge rates can be large, from about 0.1 to $100 \mathrm{~L} / \mathrm{s} / \mathrm{m}$. Moreover, the overtopping discharge rates are modulated by the propagation of surges and tides. A deterministic, waveby-wave approach is required to estimate this variability and to produce a time series of overtopping events. This is achieved with the SWAB model. However, for inundation purposes, the wave-by-wave technique may be computationally demanding, and an approach based on an averaged overtopping discharge rate could be sufficient for mapping coastal flood extent.

To assess the validity of using an averaged overtopping discharge rate for coastal flood inundation modelling, three time series were considered. Each time series, lasting 5 h, was 
(a)

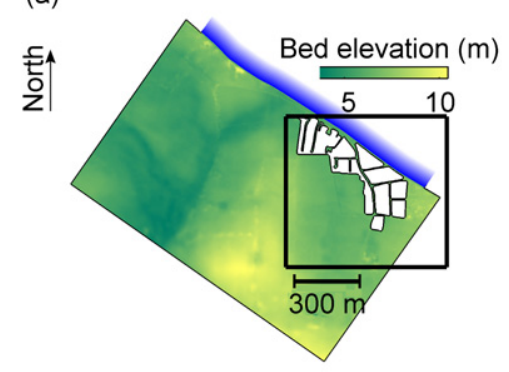

(b)

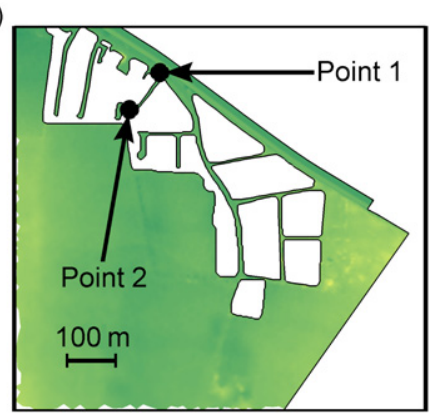

Figure 19 Topography of Walcott surrounding area (a), and showing the location of Point 1 and Point 2 where flood levels were noted.

centred on the high water level. Prior to and after this time span, no overtopping was predicted.

In Case 1, the model was run with an imposed time series of overtopping discharge rates based on a wave-by-wave analysis (see Figure. 17). This time series was then averaged either over $6 \mathrm{~h}$ (Case 2) or hourly to produce hourly mean overtopping discharge rates (Case 3 ). The averaged overtopping discharge over $6 \mathrm{~h}$ was $0.45 \mathrm{~L} / \mathrm{s} / \mathrm{m}$.

\section{TELEMAC-2D modelling and results}

To simulate the flood extent and highest water marks caused by the 9 November 2007 event, TELEMAC-2D (Hervouet, 2007) was employed to solve the depth-averaged non-linear shallow-water equations on an unstructured grid comprising 49511 nodes and 95715 triangles. The spatial resolution varied from 50 to $1 \mathrm{~m}$ to ensure that at least four nodes represent the streets between blocks and that regions of high bed gradient are well resolved. The slip condition was applied on block boundaries.

The overtopping discharge rates estimated using SWAB were input to the TELEMAC-2D model by adding to the computational domain a narrow reservoir alongside the sea wall. A width of $20 \mathrm{~m}$ was convenient. Prior to the computation, the reservoir was filled, with the water level reaching the sea wall crest level, i.e. $6.6 \mathrm{~m} \mathrm{ODN}$. The flow rates were then imposed along the seaward side of the reservoir causing an overflow over the sea wall with a discharge rate equal to that imposed with negligible phase lag due to the propagation of the bore within the reservoir; mass conservation was maintained throughout the computation. Another more direct open boundary condition was tested first, where the critical water depth and critical velocity, defined by the overtopping discharge rate, were imposed on the top of the reservoir. This method did not conserve mass and was abandoned. It would appear that TELEMAC requires subcritical inflow conditions for such applications.

The time step was set to $0.1 \mathrm{~s}$ and a uniform Manning coefficient of $0.035 \mathrm{~s} / \mathrm{m}^{1 / 3}$ was applied, an average value for urban conditions (Mignot et al., 2006). Figure 20 presents the results from the simulation in terms of the highest water mark for each case. The maximum value of the highest water mark occurred in the vicinity of the sea wall, with the water depth reaching $1.22 \mathrm{~m}$ for the wave-by-wave time series of the overtopping discharge. The highest water mark values reduce further inland. Within the flooded area, the average highest water mark was $0.4 \mathrm{~m}$.

The model predictions show that the flood extent is constrained by the local topography. Water overflowing the sea wall was transported along the coastal road towards the lowlying land west of the residential area. Then, the water flowed further inland. The three time series of overtopping discharges, imposed as boundary conditions, generated very similar flood extents. A comparison of the values of the highest water mark reached during the simulation shows that the water level was dependent on the overtopping discharge time series. Figure 21 presents the evolution of the highest water mark time series at the two points shown in Figure 19b. The wave-by-wave time series generates the maximum value of the highest water mark. Figure 21 also shows the time interval between the start of the event and the effective inundation at these locations. For Point 1, the point closest to the sea wall, the rate of increase in water level is similar for each case. At Point 2, located further inland than Point 1 , the situation was different in that the rates of inundation are more abrupt for Case 1 and Case 2. Moreover, the time interval between the inundations at Point 1 and Point 2 was about $70 \mathrm{~min}$ in Case 3, whereas it was $45 \mathrm{~min}$ for the two other cases. This indicates how quickly the flood spreads, which is important for risk management.

Two years after the event, local residents were interviewed in order to gain first-hand accounts concerning the flood extent and the observed highest water levels. Figure 22 shows residents pointing to the location of the highest water marks at Point 1 and Point 2. According to these photographs, the values of the water depth are underestimated at these locations by about $30 \mathrm{~cm}$. The inundation level and extent are, however, sensitive to the overtopping discharge uncertainty, which are in turn sensitive to uncertainty in nearshore water level and wave height, as shown in the ninth section. 

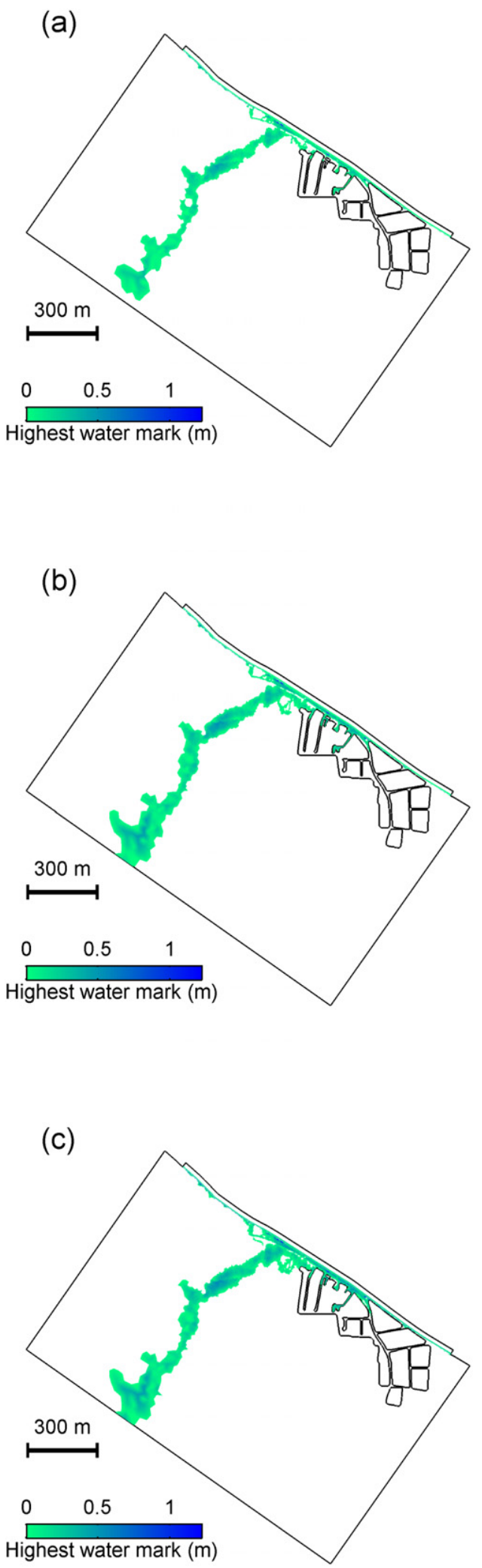

Figure 20 Highest water mark plots for mean overtopping discharge rate (a), hourly mean overtopping discharge rate (b) and wave-by-wave time series (c).

\section{Climate change and sea level rise effects}

In a changing climate with sea level rise, the frequency of occurrence of an extreme event will be modified, and quantifying this modification is of primary importance for assessing increased coastal flood risks.

To investigate the influence of climate change and sea level rise on the 2007 event occurrence, the numerical modelling framework developed by Nicholls et al. (2008) was used. This allows projections of the effect of one greenhouse gas emission scenario, SRES A1B (IPCC, 2000), and seven sea level rise rates on the hydrodynamic conditions off Walcott in 2100. Extreme value analyses were performed on the resulting long-term time series of water levels and waveintegrated parameters (Chini and Stansby, 2012). From these statistical analyses, the return period of the 2007 event can be estimated for combinations of global climatic change and sea level rise.

In order to estimate the implications of projected global climate changes, a downscaling procedure consisting of coupling several numerical models with spatial resolution ranging from several 100 to $12 \mathrm{~km}$ was performed during the UK Climate Projections 2009 (UKCP09) project (Lowe et al., 2009). These models aim to simulate the variability in water level and wave climate due to projected changes in atmospheric conditions induced by the greenhouse gas emission scenario, SRES A1B. The models were run over a period of 140 years from 1960 to 2100 . Direct validation of this procedure was not possible with past observations because the model set-up was not intended to hindcast actual past conditions. However, comparison with historical statistical values such as the mean annual significant wave height, or the 50-year return period water level, shows that the downscaling procedure was able to capture past climate variability.

To gain accuracy closer to the shoreline and to include changes in water depth due to tides and surges on coastal wave propagation, the efficient methodology proposed by Chini et al. (2010) was applied to further downscale projections towards a point less than $1 \mathrm{~km}$ off Walcott. This is based on lookup tables where data for each inshore hydrodynamic parameter of interest are generated from model runs for discrete sets of offshore parameters and then stored in tabular form to enable the value for any set of offshore conditions to be obtained simply by linear interpolation.

UKCP09 not only downscales global climate projections but also proposes a set of ensemble runs to estimate sensitivity to the climate model parameterisation. Three runs were jointly performed for both waves and water levels. One of these three runs was over 140 years from 1960 to 2100. The two remaining runs were performed for two distinct time slices corresponding to the periods from 1960 to 1990 and from 2070 to 2100 . Hereafter, these two time slices are respectively called the baseline and the future. The 140-year 

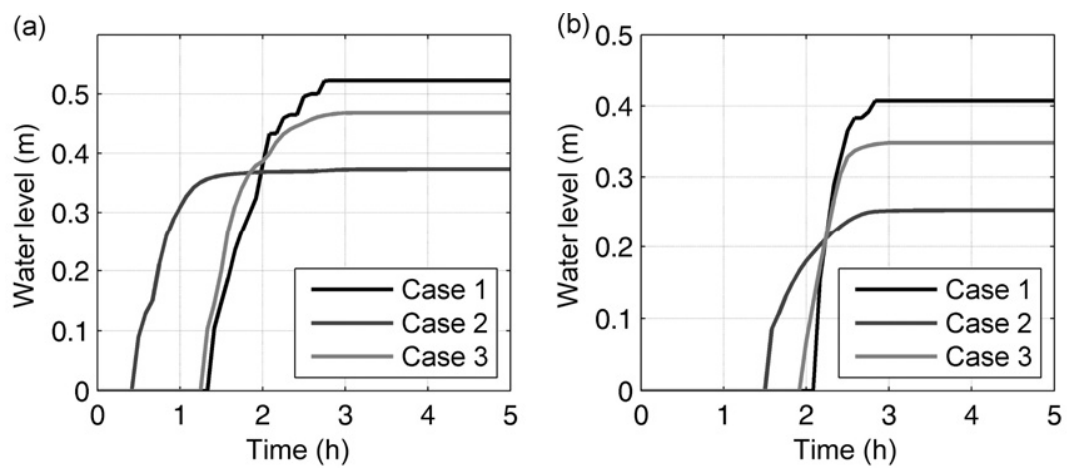

Figure 21 Time series of highest water mark from TELEMAC simulations at Point 1 (a) and Point 2 (b).
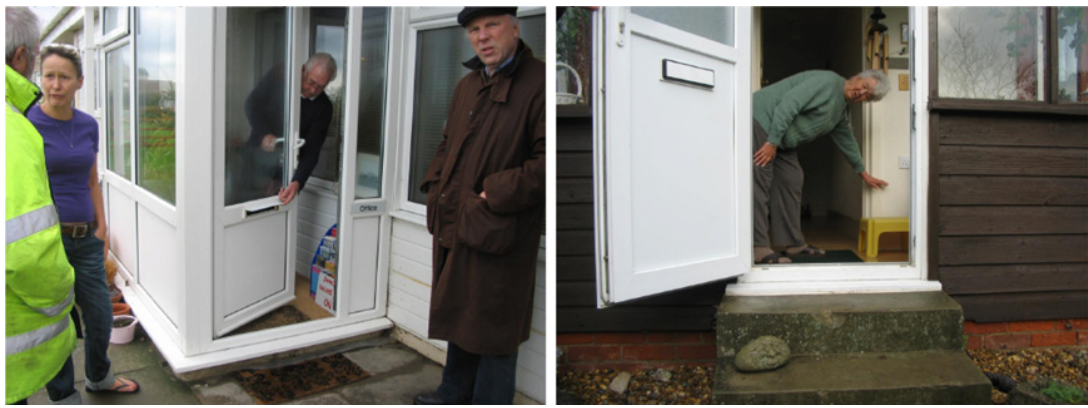

Figure 22 Photographs with Walcott residents indicating highest water mark during the event.

(a)

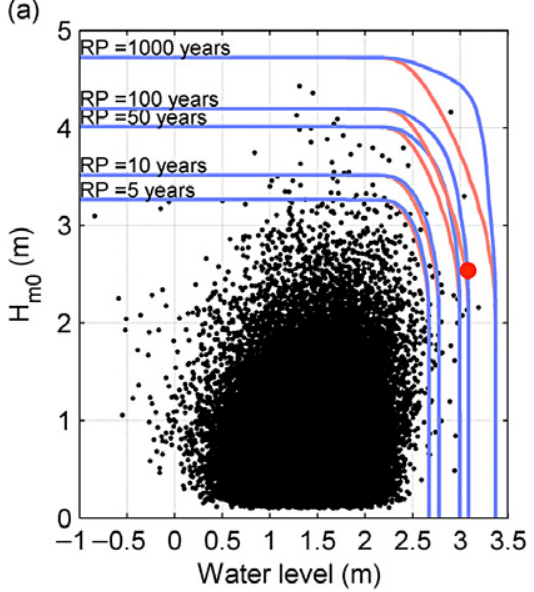

(b)

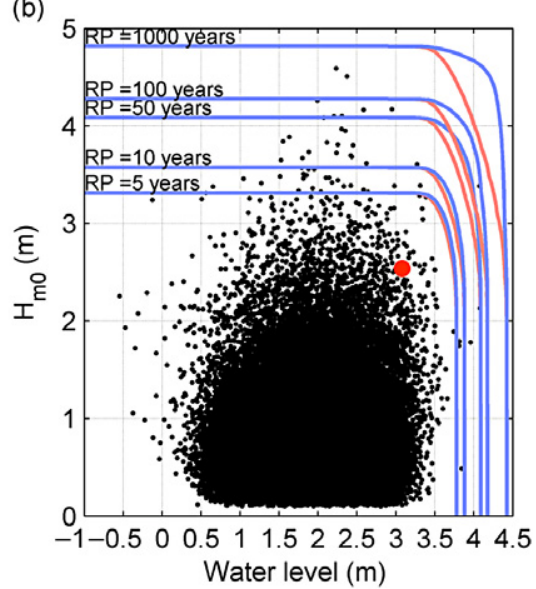

Figure 23 Scatter plot of water levels and nearshore significant wave height at Walcott from the A1B scenario without sea level rise (a) and with a $1 \mathrm{~m}$ sea level rise in 2100 (b). Lines represent the joint return level for a given return period (RP). Blue lines are with dependency between water level and wave height and for the red lines they are assumed independent. The red dot indicates the 2007 event.

run was used to assess the sensitivity to seven linear sea level rise scenarios, ranging from current conditions, $2 \mathrm{~mm} /$ year, to higher sea level rises estimated by Meehl et al. (2007). Two extreme sea level rises of 1 and $2 \mathrm{~m}$ in 2100 were also assessed. Sea level rise was linearly superimposed on the projected water levels following Lowe and Gregory (2005). A case without any sea level rise was also considered. Figure 23 presents the scatter plot of water level and wave height off Walcott for the case with no sea level rise and the one leading to a $1-\mathrm{m}$ sea level rise in 2100 . 

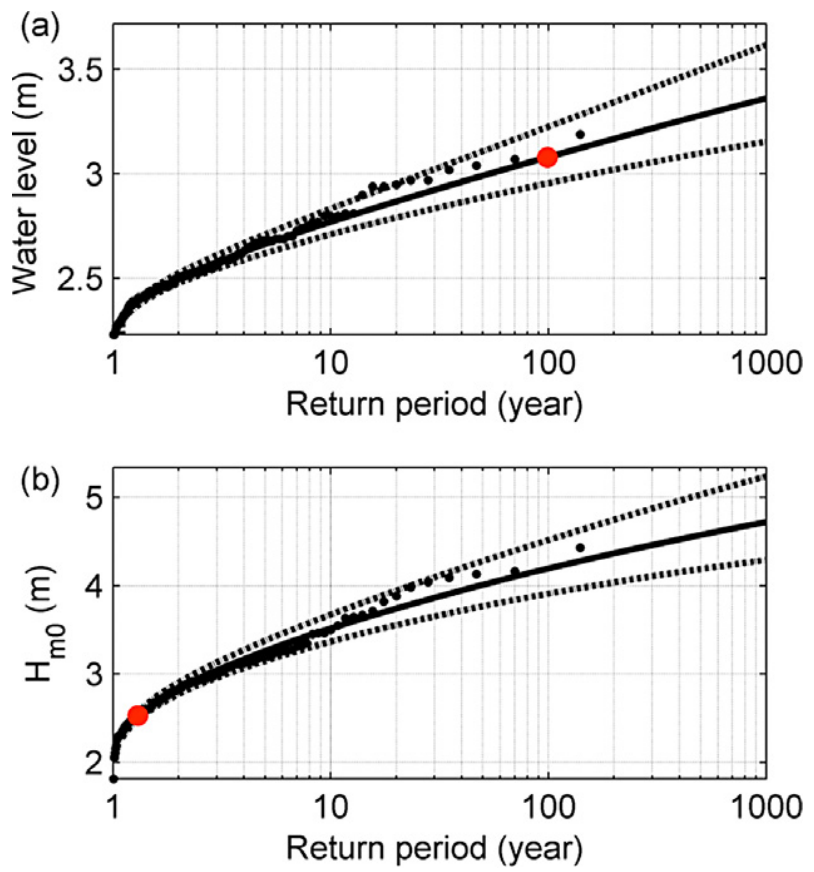

Figure 24 Return period plot for water level (a) and significant wave height (b) at Walcott. Red dots represent the return period for water level and significant wave height observed during the 2007 event.

The influence of the climate change scenario SRES A1B was analysed by comparing the results obtained by the ensemble for the future with the ones obtained for the baseline. In this case, no sea level rise was added to the water levels. Because the climate model parameterisations are considered equally probable, the average of the three runs is used to represent the climate change influence on water levels and waves.

Extreme value analysis consists of estimating the magnitude of events having a very low probability of occurrence. Techniques to assess these levels involve distribution fitting to a sample of time series. If this time series is long enough, larger than about 30 years, the extreme values can be estimated using the generalised extreme values distribution fitted to the annual $r$-largest values, where $r$ varies usually from 1 to 10 . Here, the distribution was fitted to the annual 10-largest values. The fit was performed using the maximum likelihood estimation procedure (Coles, 2001).

To assess the return period of the 9 November 2007 event, the 140-year run was considered. Figure 24 presents the return period diagram estimated for both water levels and significant waves. From the analysis, the highest water level during the 2007 event at Walcott has a return period of 98 years and the highest significant wave height a return period of 1.3 years.

Wave overtopping occurs for a combined occurrence of extreme water levels and extreme wave heights and therefore,

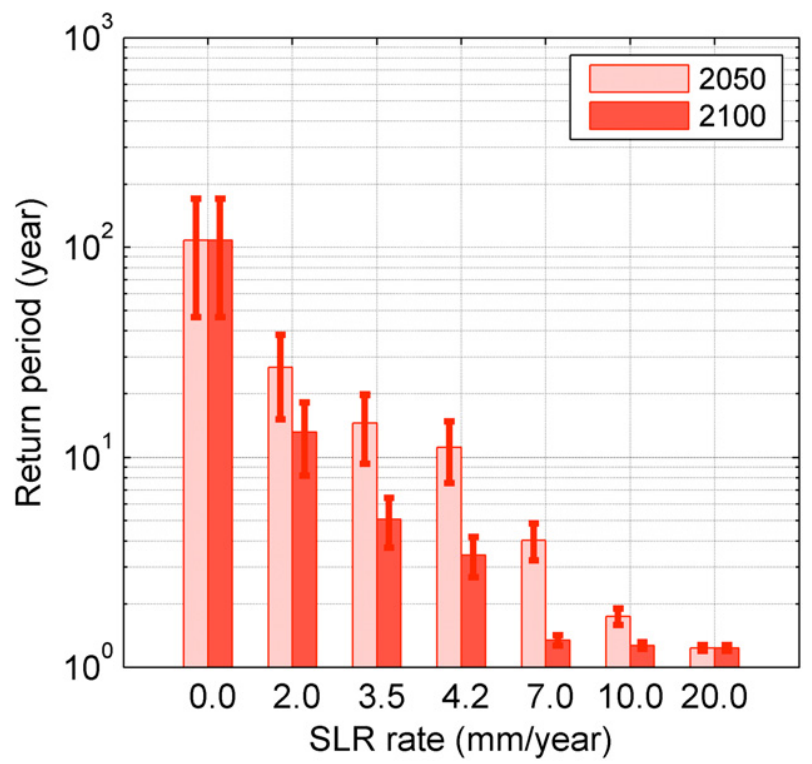

Figure 25 Change in the return period of the 2007 event with inclusion of sea level rise in 2050 and 2100.

it is dependent on the joint probability of water level and wave height. Estimation of the dependency between these two variables was performed by computing Kendall's $\tau$ for the events during the 140-year run having a probability higher than 0.1. The joint probability for waves and water levels was then estimated within the copula framework. The Archimedean Gumbel copula was chosen because it represents dependency for rare events. Small to moderate sea level rise rates do not modify the dependency parameter. Extreme water levels and extreme significant wave heights become more dependent for the high sea level rise of $20 \mathrm{~mm} /$ year, associated with reductions in wave energy losses due to deeper water at the coast (assuming no coastal change due to sedimentation). Isolines on Figure 23 represent the events having a joint return period of 5, 10, 50, 100 and 1000 years. If independency is assumed between water levels and wave heights, the values for a given return period are smaller. For instance, the water level for a 100 -year return period is almost equal to the 50-year return level when dependency between the two variables is taken into account. Not including the dependency leads to underestimation of water levels and significant wave heights for a given return period. The main inputs for coastal protection design would thus be underestimated.

Sea level rise will reduce the return period of such an event, causing future events with the same magnitude to be more frequent. Figure 25 shows the evolution of the return period of the 2007 event with sea level rise. Starting with a 108-year return period with no sea level rise, the return period becomes 13 years with a $3.5-\mathrm{mm} /$ year sea level rise in 2100 . With extreme rates of sea level rise of $0.01 \mathrm{~m} /$ year and 


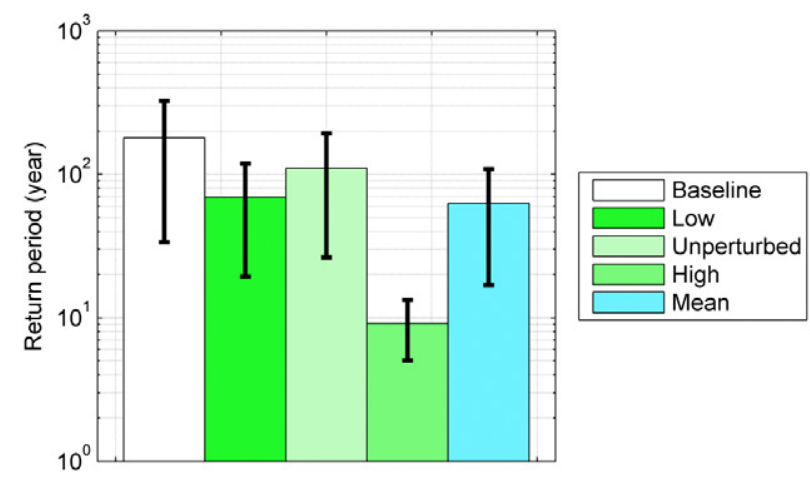

Figure 26 Change in the return period of the 2007 event with inclusion of projections from the climatic ensemble run for SRES A1B.

higher, the probability of occurrence of the 2007 event can approach one in 1 year in 2100 .

Figure 25 also presents the return periods obtained in 2050. Without sea level rise, the return period obviously remains the same in 2050 and in 2100 . However, as sea level rises, the 2007 event becomes more frequent. Differences between 2050 and 2100 values are also increasing for increasing intermediate sea level rates. For the extreme sea level rise, higher than $0.01 \mathrm{~m} /$ year, these differences are much smaller and even nil for the $0.02 \mathrm{~m} /$ year. For these extreme sea level rise rates, observing an event similar to the 2007 storm becomes more probable in 2050 and in 2100, but these probabilities are strictly beyond the range of validity of the statistical model used for extreme event analyses.

Comparison between future projections and the baseline shows that the ensemble runs induce a small reduction of the return period for water levels and an increase in significant wave height. Figure 26 presents the changes in the return period of the 2007 event for the ensemble runs. Runs constituting the ensemble were assumed equally probable, and the effect of the emission scenario was assessed by considering the average of the three runs.

\section{Uncertainties}

The ensemble runs performed during UKCP09 (Lowe et al., 2009) provide errors in climate projection associated with different climate model parameterisations. The same procedure using ensemble runs was also performed for the operational forecast of storm surges and waves. The use of perturbed-physics ensembles assumes that the modified parameters belong to a domain where the model output is sensitive to input. Given the potentially large number of parameters (in the climate model, somewhat less in surge and wave models), the ensemble should contain a large number of runs. In order to increase the computational efficiency of forecast or climate projection, the use of adjoint modelling could be considered because this modelling requires only one model integration to estimate model sensitivity. Prior to using the ensemble runs and the adjoint modelling, we propose here to test the sensitivity of the nearshore wave height to a small additive error on the input parameters: $y=f(x+\varepsilon)$ where $x$ represents the input vector (water level, offshore significant wave height, offshore peak wave period, offshore mean wave direction, ignoring the local wind forcing), $\varepsilon$ is the additive error vector and $f$ is the transfer function giving the nearshore significant wave height $y$.

Assuming $\varepsilon$ to be small, the first-order Taylor expansion of $f$ gives

$$
y=f(x)+\sum_{i=1}^{4} \frac{\partial f}{\partial x_{i}}(x) \varepsilon_{i}+o(\varepsilon) .
$$

\section{Estimation of the derivatives}

The transfer of waves towards the shore of East Anglia was performed using a lookup table coupled with a linear interpolation scheme. That means that the partial derivative of $f$ in the direction $x_{i}$ can be analytically expressed and that this derivative is, within each cell of the lookup table, independent of $x_{i}$ and bounded by the maximum of the ensemble of eight real numbers:

$$
\left\{\frac{\left|\begin{array}{c}
f\left(\bar{x}_{1}\left(a_{k}\right), \ldots, \bar{x}_{i}\left(a_{2}\right), \ldots, \bar{x}_{n}\left(a_{j}\right)\right) \\
-f\left(\bar{x}_{1}\left(a_{k}\right), \ldots, \bar{x}_{i}\left(a_{1}\right), \ldots, \bar{x}_{n}\left(a_{j}\right)\right)
\end{array}\right|}{\Delta x_{i}},\{k, j\}=1,2\right\}
$$

where $\bar{x}_{j}\left(a_{k}\right)$ represents one of the two vertices of the segment along the $j$-coordinate of the cells of the lookup table to which $x$ belongs.

In dimension 1 , the derivative is

$\frac{d f}{d x}=\frac{f(\bar{x}(b))-f(\bar{x}(a))}{\Delta}$

and in dimension 2 , the derivatives are bounded by

$$
\begin{aligned}
\left|\frac{\partial f}{\partial x_{1}}\right| \leq & \max \left\{\frac{\left|f\left(\bar{x}_{1}\left(a_{2}\right), \bar{x}_{2}\left(a_{1}\right)\right)-f\left(\bar{x}_{1}\left(a_{1}\right), \bar{x}_{2}\left(a_{1}\right)\right)\right|}{\Delta_{1}},\right. \\
& \left.\frac{\left|f\left(\bar{x}_{1}\left(a_{2}\right), \bar{x}_{2}\left(a_{2}\right)\right)-f\left(\bar{x}_{1}\left(a_{1}\right), \bar{x}_{2}\left(a_{2}\right)\right)\right|}{\Delta_{1}}\right\} \\
\left|\frac{\partial f}{\partial x_{2}}\right| \leq & \max \left\{\frac{\left|f\left(\bar{x}_{1}\left(a_{1}\right), \bar{x}_{2}\left(a_{2}\right)\right)-f\left(\bar{x}_{1}\left(a_{1}\right), \bar{x}_{2}\left(a_{1}\right)\right)\right|}{\Delta_{2}},\right. \\
& \left.\frac{\left|f\left(\bar{x}_{1}\left(a_{2}\right), \bar{x}_{2}\left(a_{2}\right)\right)-f\left(\bar{x}_{1}\left(a_{2}\right), \bar{x}_{2}\left(a_{1}\right)\right)\right|}{\Delta_{2}}\right\} .
\end{aligned}
$$

In our case, an error in the offshore conditions will induce an error in the nearshore prediction bounded by

$$
|y-f(x)| \leq 0.95 \varepsilon_{H m 0}+0.32 \varepsilon_{h}+1.18 \varepsilon_{T p}+0.035 \varepsilon_{\theta} .
$$


(a)

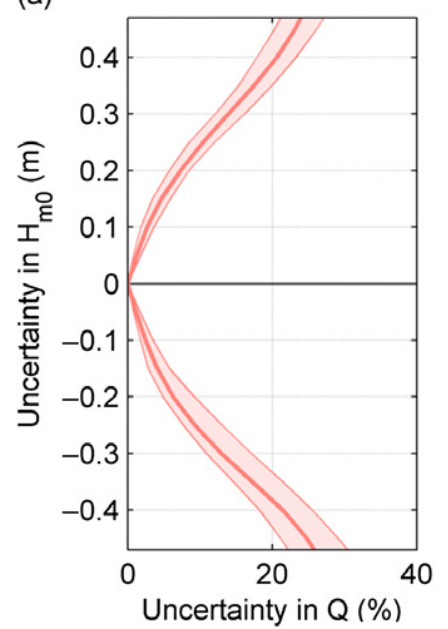

(b)

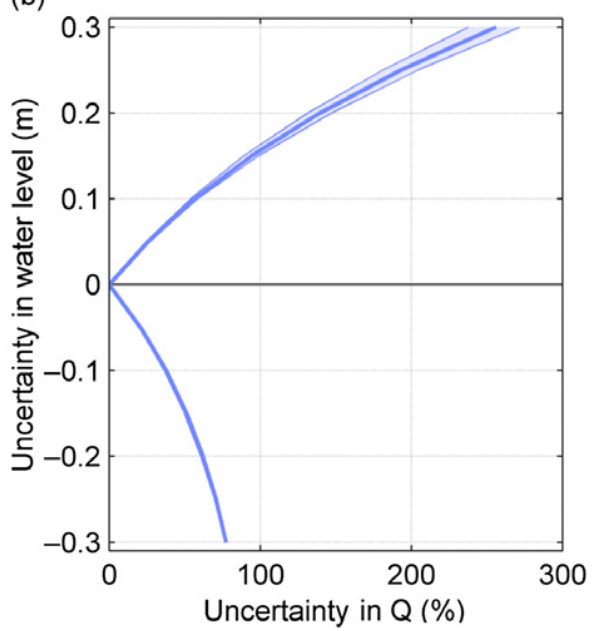

Figure 27 Induced errors in overtopping discharge rates Q due to uncertainty in offshore wave height (a) and water level (b).

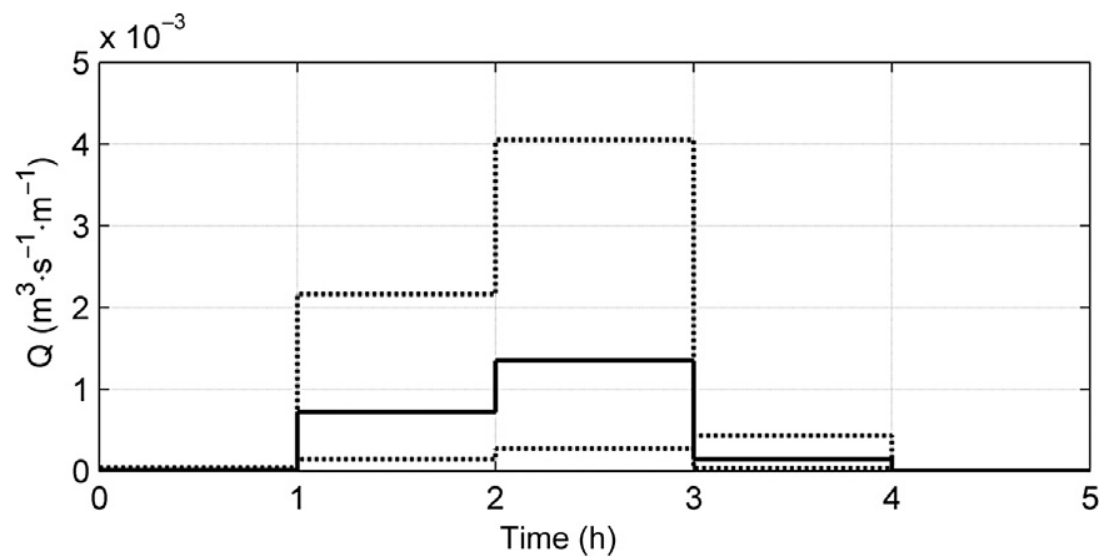

Figure 28 Time series of overtopping discharge rates with errors induced by a $\pm 10 \%$ uncertainty in offshore wave conditions and water levels, dashed lines and reference rate, full line.

This means that an error of $0.1 \mathrm{~m}$ in the offshore significant wave height will induce a maximum error of $0.095 \mathrm{~m}$ at Walcott. The relatively high sensitivity to the offshore peak wave period is misleading. In fact, this value is overestimated because the lookup table contains some relatively steep waves (with $\mathrm{Hs}=8 \mathrm{~m}$ and $\mathrm{Tp}=4 \mathrm{~s}$, for instance). By considering only the situation where wave steepness is realistically limited ( $\mathrm{ka} \leq 0.07)$, the equation becomes

$$
|y-f(x)| \leq 0.95 \varepsilon_{H m 0}+0.32 \varepsilon_{h}+0.52 \varepsilon_{T p}+0.035 \varepsilon_{\theta} .
$$

\section{Sensitivity of overtopping discharge simulated for the 2007 event to uncertainty in offshore wave conditions and water levels}

An uncertainty of $10 \%$ was added to the values of offshore wave heights and water levels simulated during the 2007 event and then propagated towards the sea wall to estimate the uncertainty on overtopping discharge predictions. This offshore $10 \%$ error represents a maximum error on nearshore significant wave height of $0.47 \mathrm{~m}$, corresponding to an $18 \%$ error nearshore. For water level, the $10 \%$ error corresponds to $0.3 \mathrm{~m}$. Figure 27 presents the error in overtopping discharge prediction for the 2007 event due to uncertainty in water levels and offshore significant wave heights. Wave height uncertainty leads to an error in overtopping discharge rate less than $30 \%$. Errors induced by uncertainty in water levels are much higher. A $+10 \%$ uncertainty in water level could increase the nominal overtopping discharge rate by a factor of 3.7. Thus, at least for that particular event, overtopping discharge predictions are mainly sensitive to water level. It may also be observed that if the $0.2 \mathrm{~m}$ overprediction of water level at Lowestoft (Figure 8) was transmitted to Walcott, the correction to discharge would be a reduction of 
about $60 \%$, further reducing the predicted inundation levels below those observed.

\section{Implications for inundation extent}

The estimated errors in overtopping discharge rates were taken into account on the input inflow for the inundation modelling. Figure 28 presents the time series of the event of 2007 , including the limits induced by the uncertainty of $\pm 10 \%$ in offshore significant wave height and water levels.

Figure 29 presents the inundation extent and the highest water mark simulated for these three overtopping discharge rates. The $-10 \%$ uncertainty run leads only to inundation close to the sea wall, and no inundation is simulated within the network of roads. The $+10 \%$ uncertainty run induced a much larger inundated area. The main street of Walcott was completely flooded.

The simulated inundation extent is dependent on the uncertainty in the overtopping discharge, and this is also the case for the highest water mark. Figure 30 shows time series of the highest water mark at Point 1 and Point 2 (see Figure 19b). As shown previously, the highest water mark is much more sensitive to the extreme overtopping discharge within the input time series. At Point 1, the uncertainties in offshore input lead to a variation of $30 \%$ in the simulated highest water mark. At Point 2, the $-10 \%$ error in offshore conditions does not induce flooding at all, whereas the highest water mark is increased by $43 \%$ for $+10 \%$ uncertainty.

\section{Conclusions}

An integrated modelling system is demonstrated for the prediction of overtopping and inundation during the flood event of 9 November 2007 at Walcott. The system involves downscaling from climate models to wave models and continental shelf models for tides and surge, to coastal models for wave propagation, to local overtopping and inundation. Coastal modelling has recently been developed, including an effective 1D time-stepping model for wave overtopping, and this is compared with EurOtop predictions. A methodology for forecasting beach profiles based on historical data has also been successfully applied. Sensitivity (or uncertainty) analysis shows that overtopping and flooding is more sensitive to water level than nearshore wave height and uncertainty in water level may be significant. Offshore surge levels at Lowestoft were overestimated, by up to $0.5 \mathrm{~m}$, just before the flood event, while the offshore water level was overestimated by up to $0.2 \mathrm{~m}$ during the flood event. The uncertainty analysis showed that such differences would cause quite different levels and extent of flooding. If the overprediction of the water level at Lowestoft were the same at Walcott, the correct water level would further reduce the

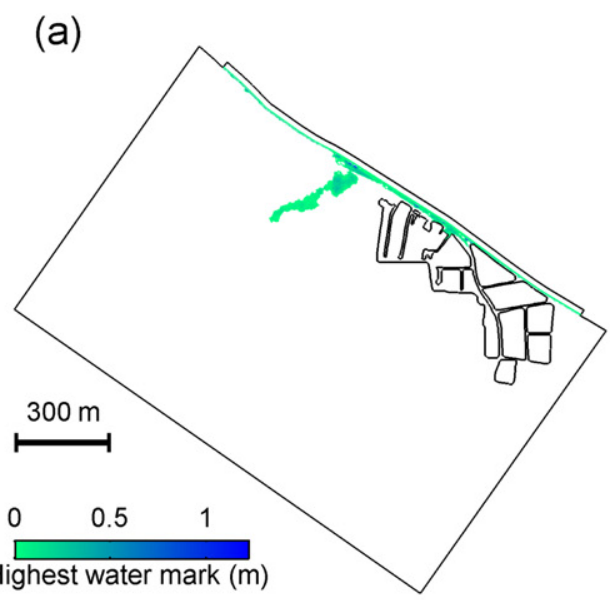

(b)

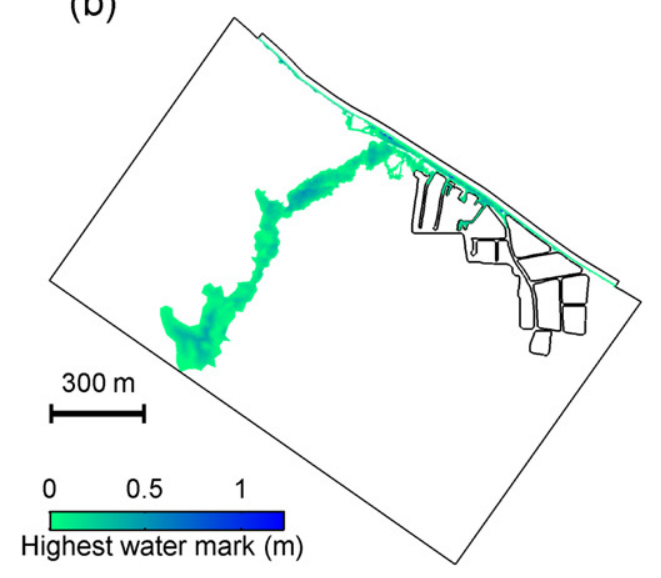

(c)

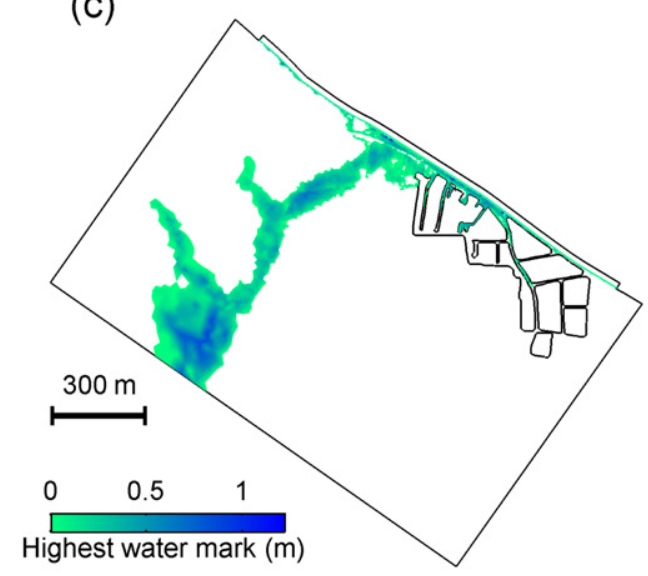

Figure 29 Simulated highest water marks with $-10 \%$ errors in water levels and offshore wave height (a), reference run (b) and $+10 \%$ errors in water levels and offshore wave height (c). 

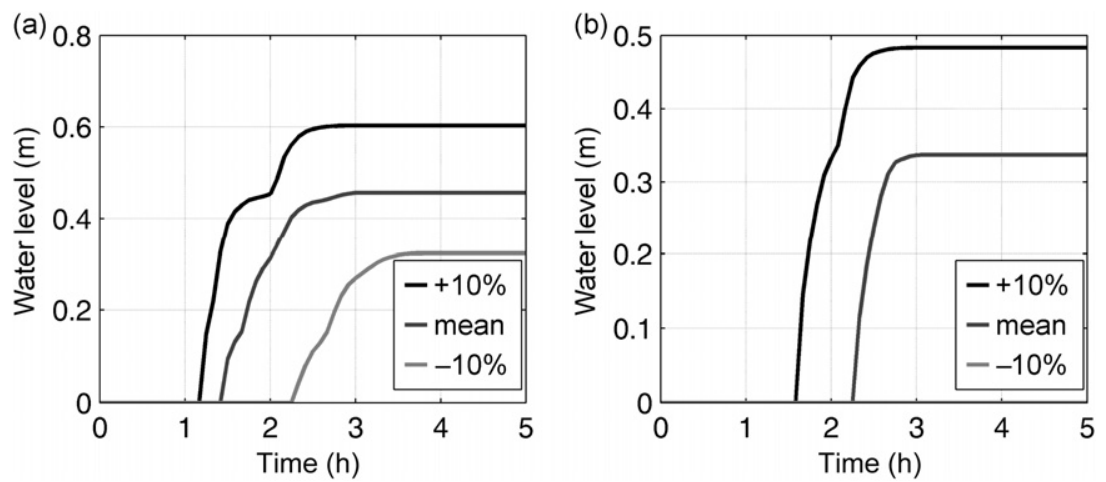

Figure 30 Simulated highest water marks time series at Point 1 (a) and Point 2 (b).

predicted inundation levels below those observed, although flooding would still have occurred. This further emphasises the limitations of modelling these complex physical processes and the need for more case studies. It is only through such integrated modelling that different natural and engineered scenarios may be assessed. An extreme value analysis indicates that the 2007 event had a return period of close to 1 in 100 years. The effect of climate change and sea level rise has also been analysed for this configuration, for example showing that a sea level rise of $0.5 \mathrm{~m}$ by 2100 will reduce the return period to below 2 years.

\section{Acknowledgements}

This work contributes to the Flood Risk Management Research Consortium. The FRMRC is supported by grant EP/F020511/1 from the Engineering and Physical Sciences Research Council, in partnership with the DEFRA/EA Joint Research Programme on Flood and Coastal Defence, UKWIR, OPW (Ireland) and the Rivers Agency (Northern Ireland). Stansby and Chini acknowledge support through the Tyndall Centre and Reeve and Horrillo-Caraballo of the European Commission through FP7.2009-1, Contract 244104 - THESEUS ('Innovative technologies for safer European coasts in a changing climate').

\section{References}

Battjes J.A. \& Janssen J.P.F. Energy loss and set-up due to breaking of random waves. International Conference on Coastal Engineering, Hamburg, 1978, 569-587.

Benoit M., Marcos F. \& Becq F. Development of a third generation shallow-water wave model with unstructured spatial meshing. 25th lnternational Conference on Coastal Engineering, Orlando, 1996, 465-478.

Booij N., Ris R.C. \& Holthuijsen L.H. A third-generation wave model for coastal regions. 1. Model description and validation. J Geophys Res 1999, 104, (C4), 7649-7666.
Brown J. \& Wolf J. Coupled wave and surge modelling for the eastern Irish Sea and implications for model wind-stress. Cont Shelf Res 2009, 29, (10), 1329-1342.

Brown J.M., Bolaños R. \& Wolf J. Impact assessment of advanced coupling features in a tide-surge-wave model, POLCOMS-WAM, in a shallow water application. J Marine Syst 2011, 87, (1), 13-24.

Brown J.M., Souza A.J. \& Wolf J. An 11-year validation of wavesurge modelling in the Irish Sea, using a nested POLCOMSWAM modelling system. Ocean Modelling 2010, 33, (1-2), $118-128$.

Caires S. \& Sterl A. A new non-parametric method to correct model data: application to significant wave height from the ERA-40 reanalysis. J Atmos Oceanic Tech 2005, 22, (4), 443459.

Cavaleri L. Wave modeling - missing the peaks. J Phys Oceanogr 2009, 39, 2757-2778.

Chini N. \& Stansby P. Extreme values of coastal wave overtopping accounting for climate change and sea level rise. Coast Eng 2012, 65, 27-37.

Chini N., Stansby P., Leake J., Wolf J., Roberts-Jones J. \& Lowe J. The impact of sea level rise and climate change on inshore wave climate: a case study for East Anglia (UK). Coast Eng 2010, 57, (11-12), 973-984.

Clark D. Understanding canonical correlation analysis. Concepts and techniques in modern geography, No.3. Norwich: Geo Abstracts Ltd, 1975.

Coles S. An introduction to statistical modelling of extreme values. Springer series in Statistics. London: Springer, 2001.

De Rouck J., Verhaeghe H. \& Geeraerts J. Crest level assessment of coastal structures - general overview. Coast Eng 2009, 56, (2), 99-107.

Dean R.G. \& Dalrymple R.A. Coastal processes with engineering applications. Cambridge: Cambridge University Press, 2002.

Dean R.G., Healy T.R. \& Dommerholt A.P. A 'blind-folded' test of equilibrium beach profile concepts with New Zealand data. Mar Geol 1993, 109, (3-4), 253-266.

DEFRA. Beach lowering in front of coastal structures. R\&D Technical Report FD1916/TR, London: DEFRA, 2005. 
Graham N.E., Michaelsen J. \& Barnett T.P. An investigation of the El Niño-southern oscillation cycle with statistical models: 1. Predictor field characteristics. J Geophys Res 1987, 92, (C13), 14251-14270.

Guza R.T. \& Thornton E.B. Wave set-up on a natural beach. J Geophys Res 1981, 96, (C2), 4133-4137.

Hasselmann K., Barnett T.P., Bouws E., Carlson H., Cartwright D.E., Enke K., Ewing J.A., Gienapp H., Hasselmann D.E., Kruseman P., Meerburg A., Mller P., Olbers D.J., Richter K., Sell W. \& Walden H. Measurements of wind-wave growth and swell decay during the Joint North Sea Wave Project (JONSWAP). Ergnzungsheft zur Deutschen Hydrographischen Zeitschrift Reihe 1973, 8, (12), 1-95.

Hervouet J.-M. Hydrodynamics of free surface flows modelling with the finite element method. Wiley, 2007.

Holt J.T. \& James I.D. An s coordinate density evolving model of the northwest European continental shelf: 1, Model description and density structure. J Geophys Res 2001, 106, (C7), 14,015-14,034.

Horrillo-Caraballo J.M. \& Reeve D.E. An investigation of the link between beach morphology and wave climate at Duck, North Carolina, USA. J Flood Risk Manage 2008, 1, (2), 110-122.

Horrillo-Caraballo J.M. \& Reeve D.E. An investigation of the performance of a data-driven model on sand and shingle beaches. Mar Geol 2010, 274, (1-4), 120-134.

Horrillo-Caraballo J.M. \& Reeve D.E. Application of a statistical method to investigate patterns of beach evolution in the vicinity of a seawall. J Coast Res SI 2011, 64, 95-99.

Horsburgh K.J., Williams J.A., Flowerdew J. \& Mylne K. Aspects of operational forecast model skill during an extreme storm surge event. J Flood Risk Manage 2008, 1, (4), 213-221.

Hotelling H. Relations between two sets of variates. Biometrika 1936, 28, 312-377.

IPCC. Special report in emissions scenarios. In: N. Nakicenovic \& R. Swart, eds. Cambridge: Cambridge University Press, 2000.

Jiang L., Borthwick A.G.L., Krámer T. \& Józsa J. Variable density bore interaction with block obstacles. Int J Comput Fluid Dyn 2011, 25, (4), 223-237.

Komen G.J., Cavaleri L., Donelan M., Hasselmann K., Hasselmann S. \& Janssen P.A.E.M. Dynamics and modelling of ocean waves. Cambridge: Cambridge University Press, 1994.

Kuang C. \& Stansby P. Efficient modelling for directional random wave propagation inshore. Marit Eng 2004, 157, (MA3), 123-131.

Lane A., Hu K., Hedges T.S. \& Reis M.T. New north east of England tidal flood forecasting system. In: P. Samuels, S. Huntington, W. Allsop \& J. Harrop, ed. Flood risk management: research and practice, Proc. FLOODrisk 2008, Oxford: CRC Press, 2009, 1377-1387.

Larsen J. \& Dancy H. Open boundaries in short wave simulations - a new approach. Coast Eng 1983, 7, 285-297.
Larson M., Capobianco M. \& Hanson H. Relationship between beach profiles and waves at Duck, North Carolina, determined by canonical correlation analysis. Mar Geol 2000, 163, 275-288.

Liang D., Falconer R.A. \& Lin B. Coupling surface and subsurface flows in a depth averaged flood wave model. J Hydrol 2007, 337, (1-2), 147-158.

Lowe J.A. \& Gregory J.M. The effects of climate change on storm surges around the United Kingdom. Philos Trans R Soc A Math Phys Eng Sci 2005, 363, (1831), 1313-1328.

Lowe J.A., Howard T.P., Pardaens A., Tinker J., Wakelin S., Milne G., Leake J., Wolf J., Horsburgh K., Reeder T., Jenkins G., Ridley J., Dye S. \& Bradley S. UK climate projections science report: marine and coastal projections. Exeter: Met Office Hadley Centre, 2009.

Madsen O.S., Poon Y.-K. \& Graber H.C. Spectral wave attenuation by bottom friction: theory. Proceedings of the 21st International Conference on Coastal Engineering. Malaga, 1988, 492-504.

Madsen P.A. \& Sørensen O.R. A new form of the Boussinesq equations with improved linear dispersion characteristics. Part 2. A slowly varying bathymetry. Coast Eng 1992, 18, 183-204.

McCabe M.V. Modelling nearshore waves, runup and overtopping. PhD Thesis, University of Manchester, Manchester, UK, 2011.

McCabe M.V., Stansby P.K. \& Apsley D.D. Coupled wave action and shallow-water modelling for random wave runup on a slope. J Hydr Res 2011, 49, 515-522.

Meehl G.A., Stocker T.F., Collins W.D., Friedlingstein P., Gaye A.T., Gregory J.M., Kitoh A., Knutti R., Murphy J.M., Noda A., Raper S.C.B., Watterson I.G., Weaver A.J. \& Zhao Z.-C. Global climate projections. In: S. Solomon, D. Qin, M. Manning, Z. Chen, M. Marquis, K.B. Averyt, M. Tignor \& H.L. Miller, ed. Climate Change 2007: The Physical Science Basis. Contribution of Working Group I to the Fourth Assessment Report of the Intergovernmental Panel on Climate Change. Cambridge, UK and New York: Cambridge University Press, 2007, 996 pp.

Mignot E., Paquier A. \& Haider S. Modeling floods in a dense urban area using 2D shallow water equations. J Hydrol 2006, 327, 186-199.

Monbaliu J., Padilla-Hernández R., Hargreaves J.C., CarreteroAlbiach J.C., Luo W., Sclavo M. \& Günther H. The spectral wave model WAM adapted for applications with high spatial resolution. Coast Eng 2000, 41, 41-62.

Nicholls R.J., Hanson S., Mokrech M., Stansby P.K., Chini N., Walkden M.J.A., Dawson R., Roche N., Hall J.W., Nicholson-Cole S., Watkinson A.R., Jude S.R., Lowe J.A., Wolf J., Leake J., Rounsevell M.D.A., Fontaine C. \& AcostaMichlik L. The Tyndall coastal simulator and interface. 31st International Conference on Coastal Engineering, Hamburg, 2008. 
North G.R., Bell T.L., Cahalan R.F. \& Moeng F.J. Sampling errors in the estimation of empirical orthogonal functions. Mon Weather Rev 1982, 110, 699-706.

Osuna P. \& Wolf J. A numerical study on the effect of wavecurrent interaction processes in the hydrodynamics of the Irish Sea. Proceedings of the 5th International Conference on Ocean Wave Measurement and Analysis: WAVES2005, Madrid, July, 2005.

Pullen T., Allsop N.W.H., Bruce T., Kortenhaus A., Schüttrumpf H. \& van der Meer J.W. EurOtop wave overtopping of sea defences and related structures - assessment manual. http:// www.overtopping-manual.com, 2007.

Różyński G. Data-driven modelling of multiple long-shore bars and their interaction. Coast Eng 2003, 48, 151-170.

Soares-Frazão S. \& Zech Y. Dam-break flow through an idealised city. J Hydr Res 2008, 46, (5), 648-658.

Soulsby R. Dynamics of marine sands. London: Thomas Telford, 1997.

Stansby P.K. Solitary wave runup and overtopping by a semiimplicit finite-volume shallow-water Boussinesq model. IAHR J Hydr Res 2003, 41, (6), 639-648.

Sumer B.M. \& Fredsøe J. The mechanics of scour in the marine environment. Advanced Series on Ocean Engineering, Volume 17, Singapore: World Scientific Publishing. 2002.
USACE (US Army Corps of Engineers). Shore protection manual. U.S. Army Waterways Experiment Station. Washington, DC: Coastal Engineering Research Center, U.S. Government Printing Office, 1984.

van Gent M.R.A., van den Boogaard H.F.P., Pozueta B. \& Medina J.R. Neural network modelling of wave overtopping at coastal structures. Coast Eng 2007, 54, (8), 586-593.

Wallingford H.R. Overstrand to Walcott strategy study. Hydrodynamics. Part II: Technical Support Information. Report EX 4692, 2002.

Wolf J. Coupled wave and surge modelling and implications for coastal flooding. Adv Geosci 2008, 17, 1-4.

Wolf J. Coastal flooding - impacts of coupled wave-surge-tide models. Nat Hazards 2009, 9, (2), 241-260.

Wolf J. \& Flather R.A. Modelling waves and surges during the 1953 storm. Philos Trans R Soc Lond A 2005, 363, 1359-1375.

Wolf J., Wakelin S.L. \& Holt J.T. A coupled model of waves and currents in the Irish Sea. Proceedings of the 12th (2002) International Offshore and Polar Engineering Conference, Kitakyushu, Japan, 2002. Vol. 3, 108-114.

Wolf J. \& Woolf D.K. Waves and climate change in the northeast Atlantic. Geophys Res Lett 2006, 33, L06604.

Yan K. Coastal flood inundation and morphodynamic change. DPhil Thesis, University of Oxford, Oxford, UK, 2010. 